Padraig Strappe ORCID iD: 0000-0003-0100-0558

\title{
Generation of a Nitric Oxide Signalling Pathway in Mesenchymal Stem Cells Promotes Endothelial Lineage Commitment
}

\author{
Nadeeka Bandara ${ }^{1,2}$, Saliya Gurusinghe ${ }^{2,3}$, Anne Kong ${ }^{1}$, Geraldine Mitchell ${ }^{1,4,6}$, Le- \\ Xin Wang ${ }^{2}$, Shiang Y $\operatorname{Lim}^{1,4}$, Padraig Strappe ${ }^{5^{*}}$ \\ ${ }^{1}$ O’Brien Institute Department, St Vincent's Institute of Medical Research, Victoria,
} Australia.

${ }^{2}$ School of Biomedical Sciences, Charles Sturt University, New South Wales, Australia.

${ }^{3}$ School of Agricultural and Wine Sciences, Charles Sturt University, New South Wales, Australia.

${ }^{4}$ Departments of Surgery, University of Melbourne at St. Vincent’s Hospital, Victoria, Australia.

${ }^{5}$ School of Health, Medicine and Applied Sciences, Central Queensland University, Queensland, Australia.

${ }^{6}$ Faculty of Health Sciences, Australian Catholic University, Victoria, Australia

*Correspondence Dr Padraig Strappe, School of Health, Medicine and Applied Sciences, Central Queensland University, Queensland 4700, Australia, Email: p.strappe@cqu.edu.au

This is the author manuscript accepted for publication and undergone full peer review but has not been through the copyediting, typesetting, pagination and proofreading process, which may lead to differences between this version and the Version of Record. Please cite this article as doi: 10.1002/jcp.28640.

This article is protected by copyright. All rights reserved. 


\begin{abstract}
Enhancing differentiation of mesenchymal stem cells (MSCs) to endothelial cells may improve their ability to vascularize tissue and promote wound healing. This study describes a novel role for nitric oxide (NO) in reprogramming MSCs towards an endothelial lineage and highlights the role of Wnt signaling and epigenetic modification by NO.
\end{abstract}

Rat MSCs were transduced with lentiviral vectors expressing endothelial nitric oxide synthase (pLV-eNOS) and a mutated caveolin gene (pLV-CAV-1 ${ }^{\mathrm{F} 2 \mathrm{~A}}$ ) to enhance NO generation resulting in increased in vitro capillary tubule formation and endothelial marker gene expression. An exogenous source of NO could also stimulate CD31 expression in MSCs. NO was associated with an arterial specific endothelial gene expression profile of Notch 1, Dll4 and Hey2 and significantly reduced expression of venous markers. Wnt signaling associated with NO was evident through increased gene expression of Wnt3a and $\beta$-catenin protein, and expression of the endothelial marker Pecam-1 could be significantly reduced by treatment with the Wnt signaling inhibitor Dkk1. The role of NO as an epigenetic modifier was evident with reduced gene expression of the methyl-transferase, DNMT1 and bisulphite sequencing of the endothelial Flt1 promoter region in NO producing MSCs showed significant demethylation compared to control cells. Finally, subcutaneous implantation of NO producing MSCs seeded in a biomaterial scaffold (NovoSorb $\left.{ }^{\circledR}\right)$ resulted in survival of transplanted cells and formation of blood vessels.

This article is protected by copyright. All rights reserved. 
In summary, this study describes, NO as a potent endothelial programming factor which acts as an epigenetic modifier in MSCs and may provide a novel platform for vascular regenerative therapy.

\section{Graphical Abstract}

Gene modification of mesenchymal stem cells with endothelial nitric oxide synthase and a caveolin mutant results in generation of endothelial like cells. Nitric oxide produced from MSCs was associated with Wnt signalling and affected epigenetic modification through down regulation of DNMT1. Subcutaneous transplantation of Nitric oxide producing MSCs resulted in neovessel formation.

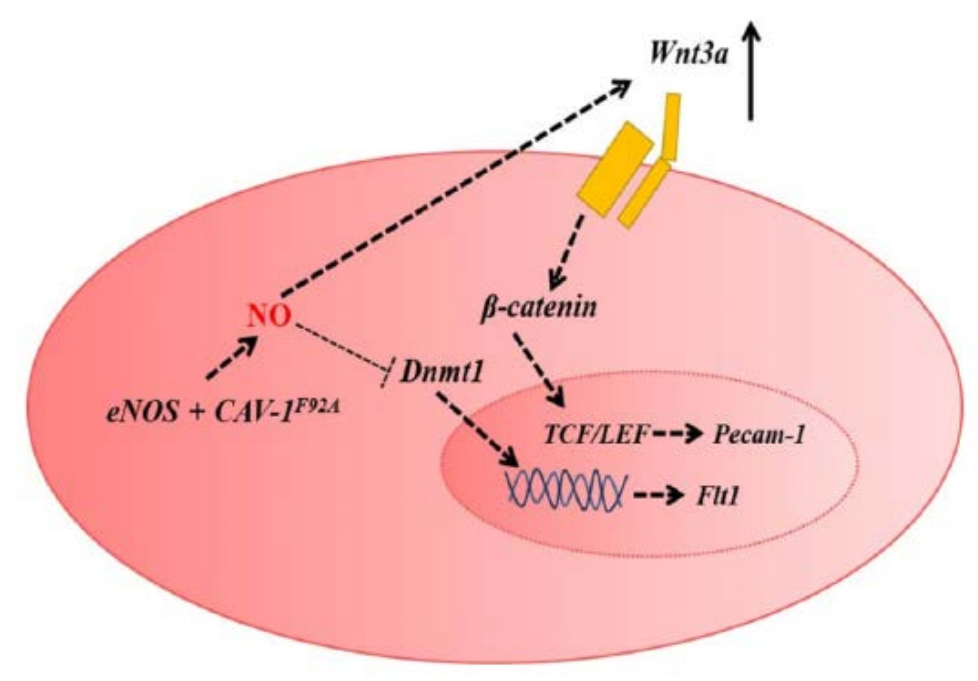

\section{Introduction}

Vascular disease is a leading cause of mortality worldwide. According to the world health organization, more than one out of three suffer from vascular related diseases and it has been estimated that 116 million people will suffer from vascular-related diseases by 2030. Therefore, a promising area of research is the generation of therapeutic cell types which can be used to generate new blood vessels. Mesenchymal stem cells (MSC) have a proliferation capacity and the potential to differentiate into vascular endothelial and smooth muscle cells under appropriate induction conditions (Bronckaers et al., 2014).

This article is protected by copyright. All rights reserved. 
Thus, MSCs have emerged as a promising cell source for regenerative medicine-based approaches to treat various disorders such as myocardial infarction, type 1 diabetes, bone disorders, liver disease and kidney damage (Bronckaers et al., 2014; Hou, Kim, Woo, \& Huang, 2016; Patel, Shah, \& Srivastava, 2013). The regenerative capacity of MSCs is also attributed to their ability to secrete various trophic cytokine factors that promote angiogenesis, inhibit apoptosis and modulate immunoreaction (Boomsma \& Geenen, 2012; Hsiao et al., 2012).

Previous studies have demonstrated that somatic cell identity can be converted to another by direct trans-differentiation which can be achieved by forced expression of lineagespecific transcription factors, as demonstrated by the successful cell-fate switching of fibroblasts into neurons, hepatocytes, pancreatic cells and cardiovascular cells (Xu, Du, \& Deng, 2015). In addition, it has been reported that small molecules can also be used to reprogram fibroblasts into cardiomyocytes (Cao et al., 2016) and endothelial cells (Lian et al., 2014) by modulating cellular signaling pathways.

Nitric oxide (NO) is a signaling molecule with a short half-life (Ignarro, Buga, Wood, Byrns, \& Chaudhuri, 1987; Vaughn, Kuo, \& Liao, 1998) and is synthesized from Larginine by nitric oxide synthases one of which is eNOS (Thomas, 2015). eNOS is localized mainly in specific intracellular membrane domains, including the Golgi apparatus(Iwakiri et al., 2006) and plasma membrane caveolae through interaction with caveolin-1 (CAV-1) (P. Bernatchez, Sharma, Bauer, Marin, \& Sessa, 2011). Direct interaction of eNOS with CAV-1 has been shown to inhibit eNOS activation, whilst a mutated version of CAV-1 with a phenylalanine to alanine substitution at the amino acid position $92\left(\mathrm{CAV}-1^{\mathrm{F} 92 \mathrm{~A}}\right)$ resulted in increased NO production (P. Bernatchez et al., This article is protected by copyright. All rights reserved. 
2011). NO regulates various physiological effects such as blood pressure via smooth muscle relaxation, controlling cell proliferation, modulating apoptosis, promoting growth factor-induced angiogenesis, and accelerating wound healing (Mujoo, Krumenacker, \& Murad, 2011). Delivery of F92A mutated CAV-1 peptides have been shown to increase eNOS-derived NO synthesis and promote vascularization in mice (P. Bernatchez et al., 2011). The importance of eNOS for physiological function of arterial vessels has been shown through impairment of blood vessel development in eNOS-deficient mice (Rennie, Rahman, Whiteley, Sled, \& Adamson, 2015). Furthermore, Yang et al. demonstrated that inhibition of Jak2, an upstream component of eNOS, attenuates endothelial function due to repression of eNOS (Yang et al., 2013). Similarly, endothelial-specific Gab1 knockout mice display marked decrease in eNOS activation and impaired angiogenesis (Lu et al., 2011).

Canonical Wnt signaling plays an important role in mesoderm commitment during embryogenesis (Tam \& Loebel, 2007) and has been shown to be a key pathway in directing differentiation of human pluripotent stem cells towards mesoderm lineage, including cardiomyocytes and endothelial cells (Lian et al., 2014; Lian et al., 2012; Sumi, Tsuneyoshi, Nakatsuji, \& Suemori, 2008). Pharmacological activation of the canonical Wnt pathway through lithium has been shown to promote retinal vascular development in mice, in which treatment of Lrp5 knockout mice with lithium was able to restore canonical Wnt signaling and promote vascular development (Wang et al., 2016). The importance of Wnt/ $\beta$-catenin signaling has been further demonstrated in human MSCs, in which MSCs deficient in $\beta$-catenin fail to differentiate into endothelial cells in vitro and showed impaired vasculogenesis in vivo (Z. Zhang et al., 2016).

This article is protected by copyright. All rights reserved. 
In this study we aimed to establish an endothelial specific eNOS-NO signaling pathway in rat bone marrow-derived mesenchymal stem cells (BMSCs) via lentiviral vector expression of eNOS and a mutated (F92A) caveolin gene and to evaluate its effect on promoting endothelial differentiation. To regulate eNOS-mediated NO signaling, interactions between eNOS and CAV-1 ${ }^{\mathrm{WT}}$ or CAV-1 ${ }^{\mathrm{F} 92 \mathrm{~A}}$ were recreated in BMSCs and our findings demonstrate for the first time that increased level of NO through coexpression of eNOS and CAV-1 ${ }^{\mathrm{F9} 2 \mathrm{~A}}$ interaction can induce endothelial differentiation, specifically towards an arterial endothelial cell subtype, via activation of the downstream Wnt/ $\beta$-catenin signaling pathway and promoting endothelial specific Flt1 gene expression.

Materials and methods

Cell cultures

Rat BMSCs were isolated from bone marrow as described previously (McGinley et al., 2011). All sampling was carried out using protocols approved by the Animal Ethics Committee of St. Vincent's Hospital (Melbourne, Australia) and were conducted in accordance with the Australian National Health and Medical Research Council guidelines for the care and maintenance of animals. Human embryonic kidney 293T cells (HEK293T) (ATCC, VA, USA) and BMSCs were cultured in DMEM medium supplemented with $10 \%$ fetal bovine serum (Sigma-Aldrich, MO, USA), $100 \mathrm{U} / \mathrm{mL}$ penicillin (Lonza, MD, USA), $100 \mu \mathrm{g} / \mathrm{mL}$ streptomycin (Lonza, MD, USA), and $2 \mathrm{mM}$ L-glutamine (Thermo Fisher Scientific, MA, USA), at $37^{\circ} \mathrm{C}$ in a humidified $5 \% \mathrm{CO}_{2}$ incubator.

This article is protected by copyright. All rights reserved. 


\section{Lentiviral vector constructs}

Lentiviral plasmids used in this study are listed in supplementary table 1 and were used for construction of lentiviral vectors. HF Phusion DNA polymerase (New England Biolabs, MA, USA) was used for all the polymerase chain reactions (PCRs) and all restriction endonucleases were purchased from New England Biolabs unless stated otherwise. To generate an eNOS-GFP fusion expression lentiviral vector, a codon optimized cDNA of human eNOS was amplified using forward (5'-ATCAGAATTCATGGGCAACCTGAA-3') and reverse (5'ATCAGGATCCCCATCAGGGGCTGT-3') primers by introducing EcoR1 and BamH1 restriction sites (underlined sequences in both forward and reverse primers) at both the 5' and 3' ends to the final PCR product, followed by subcloning into the lentiviral plasmid pLVX-GFP (Clontech, Mountain View, CA, USA) at the EcoR1 and BamH1 restriction sites downstream to the CMV promoter. The cloning was confirmed by double digestion of the resulted plasmid encoding eNOS with EcoR1 and BamH1 yielding a fragment of $\sim 3.7 \mathrm{~kb}$ (Figure 1). Human wild type CAV-1 $\left(\mathrm{CAV}-1^{\mathrm{WT}}\right)$ and the mutated CAV-1 $\left(\mathrm{CAV}-1^{\mathrm{F} 92 \mathrm{~A}}\right)$ expressing lentiviral vectors were constructed as described previously (Bandara et al., 2016). For the Flt1-GFP reporter construct, a 1049 bp fragment of the endothelial-specific Flt1 promoter region was synthesized (GenScript, NJ, USA) and sub-cloned into the pTRIP-eGFP lentiviral vector at the Mlu1 and BamH1 restriction sites replacing a rat insulin promoter, upstream of the enhanced GFP (eGFP) coding sequence.

This article is protected by copyright. All rights reserved. 


\section{Lentiviral vector production}

The lentiviral vectors used in this study (Supplementary Table 1) were generated by four plasmid transfections of HEK293T cells as previously described (Bandara et al., 2016). Briefly, HEK293T cells were seeded on a DL-lysine (Sigma-Aldrich) coated surface at a density of $1 \times 10^{5}$ cells $/ \mathrm{cm}^{2}, 24$ hours prior to transfection. $6.3 \mu \mathrm{g}$ of packaging plasmid psPAX2 (Addgene, MA, USA), $3.1 \mu \mathrm{g}$ of Rev expression plasmid pRSV Rev (Addgene), $3.5 \mu \mathrm{g}$ of VSV-G envelope expression plasmid pMD2.G (Addgene), and $10 \mu \mathrm{g}$ of the gene of interest expression transfer vector were delivered to 293T cells using a standard calcium phosphate transfection method (Tiscornia, Singer, \& Verma, 2006). Seventeen hours post-transfection, the media was changed and supernatant containing lentiviral particles was collected at 48 and 72 hours post-transfection, combined, and filtered through a $0.45 \mu \mathrm{M}$ PVDF filter. Lentiviral particles were then concentrated using PEG-it Virus Precipitation solution (System Biosciences, CA, USA).

\section{Endothelial programming}

BMSCs were seeded at $8 \times 10^{3}$ cells/ $\mathrm{cm}^{2}$ overnight, followed by transduction with eNOSGFP or GFP lentiviral vectors for 72 hours in the presence of $4 \mu \mathrm{g} / \mathrm{mL}$ polybrene (SigmaAldrich). GFP positive cells were then isolated using a flow cytometer and sorter (FACSAria, BD Biosciences, USA) and cultured in growth medium for 6 days. GFP positive cells were then seeded at $8 \times 10^{3}$ cells $/ \mathrm{cm}^{2}$ overnight, followed by a second transduction with CAV-1 ${ }^{\mathrm{WT}}$ or CAV-1 ${ }^{\mathrm{F} 2 \mathrm{~A}}$ lentiviral vectors in growth medium for 72 hours (Figure 2a).

This article is protected by copyright. All rights reserved. 
In vitro capillary tubule formation assay

Pre-chilled 96-well plates were coated with $50 \mu \mathrm{L}$ per well of Geltrex ${ }^{\mathrm{TM}}$ (Thermo Fisher Scientific) and incubated for 30 minutes at $37^{\circ} \mathrm{C}$. Cells were resuspended in DMEM medium containing $1.5 \%$ fetal bovine serum, $100 \mathrm{U} / \mathrm{mL}$ penicillin, $100 \mu \mathrm{g} / \mathrm{mL}$ streptomycin and $2 \mathrm{mM} \mathrm{L-glutamine} \mathrm{and} \mathrm{seeded} \mathrm{at} 1.2 \times 10^{4}$ cells per well. Cells were incubated at $37^{\circ} \mathrm{C}$ for 4 hours to allow capillary network formation and then fixed with 4\% paraformaldehyde.

\section{Quantitative real time PCR (RT-qPCR)}

Total RNA from lentiviral transduced and control cells was isolated using TriReagent (Thermo Fisher Scientific) according to the manufacturer's instructions and the concentration of isolated RNA was determined using a Nanodrop spectrophotometer

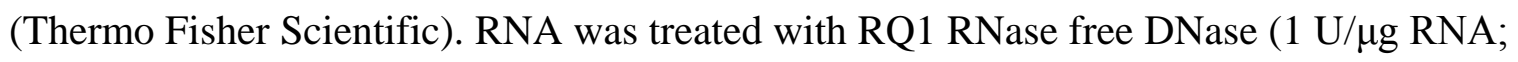
Promega, WI, USA). cDNA was synthesized with $1 \mu \mathrm{g}$ RNA from all samples using a High Capacity Reverse Transcription Kit (Thermo Fisher Scientific). Quantitative realtime PCR assays were performed on a QuantStudio ${ }^{\mathrm{TM}} 6$ Flex Real-Time PCR System (Thermo Fisher Scientific) using the SsoFast EvaGreen Supermix (Bio-Rad, CA, USA).

Primer sequences used for target gene amplification are listed in supplementary table 2 . Assays were performed in duplicate and target gene expression was normalized to rat GAPDH mRNA levels using the $\Delta \Delta \mathrm{C}_{\mathrm{t}}$ method.

\section{Western blot analysis}

Cells were washed with ice-cold PBS (Sigma-Aldrich) twice and lysates were prepared by homogenization in RIPA buffer supplemented with protease inhibitors (SigmaAldrich). Protein samples were mixed with NuPAGE LDS sample buffer (Thermo Fisher

This article is protected by copyright. All rights reserved. 
Scientifics) and denatured by heating for 10 minutes at $70^{\circ} \mathrm{C}$. Total proteins were electrophoresed on 4-12\% Bis-Tris NuPAGE gel (Thermo Fisher Scientific) and transferred to a PVDF membrane (Merck Millipore, MA, USA). After blocking with odyssey blocking buffer (LI-COR Biosciences, NE, USA) for 30 minutes at room temperature, the membrane was incubated with primary antibodies specific to eNOS (1:1000 dilution; Abcam, Cambridge, UK), p-eNOS (1:1000 dilution; Cell Signaling Technology, MA, USA), CAV-1 (1:1000 dilution; Cell Signaling Technology), Akt (1:1000 dilution; Cell Signaling Technology), $\beta$-catenin (1:1000 dilution; Cell Signaling Technology) and $\beta$-actin (1:1000 dilution; LI-COR Biosciences) overnight at $4^{\circ} \mathrm{C}$. The membrane was then washed with PBS containing 0.1\% Tween-20 and incubated with donkey anti-rabbit IgG (H\&L) (Alexa Fluor $\left.{ }^{\circledR} 680\right)$ or goat anti-mouse IgG (H\&L) (Alexa Fluor ${ }^{\circledR}$ 680) secondary antibodies (1:20000 dilution; Thermo Fisher Scientific) at room temperature for 1 hour. Immunoreactive bands were visualized using an Odyssey membrane imaging system (LI-COR Biosciences).

\section{Flow cytometry analysis}

BMSCs were seeded at $8 \times 10^{3}$ cells $/ \mathrm{cm}^{2}$ overnight, followed by transduction with eNOS lentiviral vectors for 72 hours in the presence of $4 \mu \mathrm{g} / \mathrm{mL}$ polybrene, followed by a second transduction with $\mathrm{CAV}-1^{\mathrm{F} 92 \mathrm{~A}}$ lentiviral vector for another 72 hours. Cells were then cultured in growth medium for 2 days and subjected to flow cytometry analysis. Briefly, cells were then trypsinized and washed with FACS buffer (PBS containing 0.5\% bovine serum albumin and $2 \mathrm{mM}$ ethylenediaminetetraacetic acid) and fixed in $4 \%$ paraformaldehyde in PBS for 10 minutes. Cells were then re-suspended in $100 \mu \mathrm{L}$ of flow cytometry permeabilization/wash buffer 1 (BD Biosciences, CA, USA) and $5 \mu \mathrm{L}$ of

This article is protected by copyright. All rights reserved. 
PE conjugated CD31 antibody (BD Biosciences) and incubated at room temperature for 30 minutes in the dark. The stained cells were then washed twice with flow cytometry permeabilization/wash buffer 1, resuspended in $200 \mu \mathrm{L}$ of FACS buffer and analyzed using a BD LSRFortessa ${ }^{\mathrm{TM}}$ cell analyser (BD Biosciences).

\section{Nitric oxide detection}

Extracellular NO production was measured using the Griess reagent (Promega, WI, USA) according to the manufacturer's instructions and measurement of absorbance at $540 \mathrm{~nm}$. Triplicates of each sample were measured.

\section{Bisulfite sequencing}

Lentiviral transduced cells were harvested by trypsinization, and genomic DNA was extracted using a DNeasy blood tissue kit (Qiagen, Hilden, Germany) and bisulfite converted (500 ng of DNA per reaction) using the EZ DNA Methylation-Gold Kit (Zymo Research, CA, USA). Rat Flt1 promoter region was predicted using Ensemble genome browser and the $\mathrm{CpG}$ islands within the Flt1 promoter were predicted using BiQ Analyser software (Daniel Becker, 2014). MethPrimer software was used to design the primers to amplify the Flt1 promoter region (Primers are listed in supplementary information table 3). 50 ng of bisulfite converted DNA was used for PCR amplification of the Flt1 promoter region with the GoTaq polymerase (Promega, Madison, WI, USA). The PCR products were then purified and TA-cloned into a pMiniT ${ }^{\mathrm{TM}} 2.0$ vector (New England Biolabs, MA, USA). Successful clones for each sample were then selected, cultured and subjected to Sanger sequencing.

This article is protected by copyright. All rights reserved. 
Subcutaneous implantation of cell-containing scaffolds

Experimental procedures were approved by the Animal Ethics Committee of St. Vincent's Hospital (Melbourne, Australia) and were conducted in accordance with the Australian National Health and Medical Research Council guidelines for the care and maintenance of animals. Male nude rats were purchased from Animal Resources Centre (Western Australia, Australia) and maintained with a 12 hours light/dark cycle and food and water were available ad libitum. NovoSorb ${ }^{\circledR}$ scaffolds $(6 \mathrm{~mm}$ diameter and $1.4 \mathrm{~mm}$ thick, PolyNovo, Victoria, Australia) containing 200,000 BMSCs suspended in $25 \mu \mathrm{L}$ of human fibrinogen (30 mg/mL in PBS, Sigma-Aldrich) were transplanted subcutaneously on either side of the dorsum of nude rats under general anesthesia (2\% isoflurane) as previously described (E. C. Chan et al., 2016). At 7 days post-implantation, scaffolds were harvested and fixed in $4 \%$ paraformaldehyde for 4 hours at room temperature before being embedded in $1.5 \%$ agarose containing $3.7 \%$ formaldehyde. After subjected to tissue processing, tissues were divided into equal transverse sections and paraffin embedded for histology and immunohistochemistry.

Immunohistochemistry

Paraffin embedded sections $(5 \mu \mathrm{m})$ were stained with hematoxylin and eosin for general tissue morphology. To identify blood vessels in scaffolds, endogenous peroxidase activity of sections was quenched with $3 \% \mathrm{H}_{2} \mathrm{O}_{2}$ for 10 minutes followed by enzymatic-mediated antigen retrieval with Proteinase K (Dako, Hamburg, Germany) for 5 minutes. Sections were then blocked in serum-free blocking solution (Ultra-V block, Thermo Fisher Scientific) for 5 minutes, and then incubated with biotinylated Griffonia Simplicifolia lectin (Vector Laboratories, CA, USA) overnight at $4^{\circ} \mathrm{C}$ followed by HRP-streptavidin

This article is protected by copyright. All rights reserved. 
(Dako) for 30 minutes at room temperature. The sections were then counterstained with hematoxylin. Quantification of tissue vascularization was performed using video microscopy with a computer-assisted stereo investigator system (MBF Bioscience, VT, USA). Transverse sections of scaffolds were analyzed in a blinded fashion with a 20x magnification objective with a computer-generated 12-point square grid and $25 \%$ of the total area. Percentage of vascular volume were determined by dividing the number of points falling over lectin positive vessels (including the lumens) by the total number of points counted for that tissue section and multiplied by 100 .

To identify GFP positive transplanted cells, tissue sections were subjected to heatmediated antigen retrieval in citric acid buffer (pH 6.0) for 30 minutes at $95^{\circ} \mathrm{C}$, followed by $3 \% \mathrm{H}_{2} \mathrm{O}_{2}$ for 5 minutes. Sections were then incubated in serum-free blocking solution (Ultra-V block) for 5 minutes followed by incubation with anti-GFP antibody (1:200 dilution, Santa Cruz Biotechnology, TX, USA) overnight at $4^{\circ} \mathrm{C}$. The sections were then incubated with biotinylated rabbit-anti-mouse secondary antibody (1:200 dilution, Dako) for 60 minutes, followed by avidin-biotinylated-peroxidase complex (Vectastain Elite ABC kit, Vector Laboratories) for 30 minutes at room temperature. Peroxidase activity was visualized with diaminobenzidine (Thermo Fisher Scientific) and sections were then counterstained with hematoxylin before mounting.

\section{Statistical analysis}

Data are presented as mean \pm SEM. Data were analyzed using an unpaired t-test or oneway analysis of variance (ANOVA) and Tukey's post hoc test where appropriate. All tests were performed using the statistical software Graphad Prism 6 (GraphPad, LaJolla, CA, USA). $p<0.05$ was considered statistically significant.

This article is protected by copyright. All rights reserved. 


\section{Results}

\section{Construction and validation of a GFP fused eNOS lentiviral vector}

First, the successful construction of an eNOS-GFP fusion expression lentiviral vector, was confirmed by double digestion of the lentiviral plasmid encoding eNOS with EcoR1 and BamH1 yielding a fragment of $~ 3.7$ kb (Fig. 1a). Next, lenti eNOS-GFP construct was used to generate lentiviral vectors which were used to transduce BMSCs to confirm protein expression and function. Protein expression was assessed by western blot analysis (Fig. 1b) and immunostaining (Fig. 1c) confirming the expression of eNOS protein only in eNOS transduced cells but not in GFP transduced or untransduced cells (Fig. 1b and 1c). Finally, nitric oxide production was assessed by Griess assay showing an increased level of nitrite in eNOS-GFP transduced cells compared to GFP transduced and untransduced cells (Fig. 1d).

A gene modified BMSC system to study endothelial differentiation

To select a homogenous population of lentiviral eNOS transduced cells, a C-terminal GFP fused eNOS coding region in a lentiviral vector background was designed and used to transduce BMSCs. GFP fluorescing cells were then selected by fluorescence activated cell sorting (FACS), representing eNOS-expressing cells (Supplementary Fig S1a) (eNOS-GFP expressing BMSCs designated as BMSC ${ }^{\text {eNOS-GFP }}$ ). As a control a GFP expressing lentiviral vector was used to transduce BMSCs followed by FACS analysis (Supplementary Fig S1b). The sorted eNOS-GFP (Supplementary Fig S1d, BMSC ${ }^{\text {eNOS- }}$ ${ }^{\text {GFP }}$ ) and GFP (Supplementary Fig S1e, BMSC ${ }^{\mathrm{GFP}}$ ) cells were replated and observed after $24 \mathrm{~h}$ by fluorescence microscopy. Un-transduced cells were used as a negative control for GFP expression (Supplementary Fig S1c; BMSC ${ }^{\mathrm{WT}}$ ). 


\section{eNOS gene transfer promotes eNOS-NO signalling in BMSCs}

The NO signalling pathway in the eNOS expressing cells was analysed by western blot analysis of protein expression together with treatment of cells with L-NAME an inhibitor

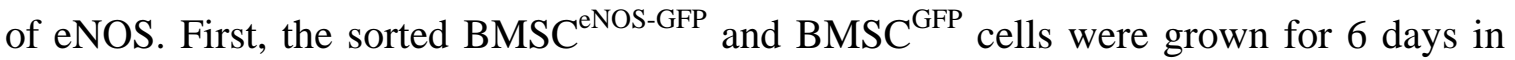
growth medium and then transduced separately with lentiviral vectors expressing either $\mathrm{CAV}-1^{\mathrm{WT}}$ or $\mathrm{CAV}-1 \mathrm{~F}^{92 \mathrm{~A}}$ (Fig. $2 \mathrm{a}$ ). The cells were then incubated for another $72 \mathrm{~h}$ and analysis of proteins involved in NO signalling was performed. Firstly, the expression of eNOS was only evident in BMSC ${ }^{\text {eNOS-GFP }}$ cells and was not affected by co-transduction with either $\mathrm{CAV}-1^{\mathrm{WT}}$ or CAV $-1^{\mathrm{F} 2 \mathrm{~A}}$ (Fig. 2b). Cells expressing only CAV-1 ${ }^{\mathrm{WT}}$ or CAV$1^{\mathrm{F} 92 \mathrm{~A}}$ did not show eNOS expression (Fig. 2b). Treatment with $2 \mathrm{mM}_{\mathrm{L}}$-NAME (NOS

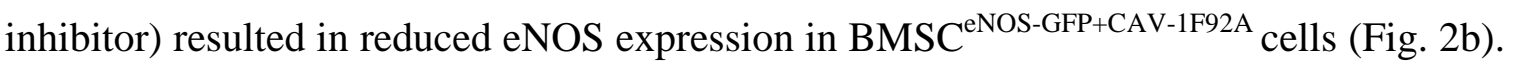
Interestingly, phosphorylation of eNOS at the serine ${ }^{1177}$ residue was markedly increased with eNOS-GFP+CAV-1 ${ }^{\text {F92A }}$ co-transduction and, decreased with eNOS-GFP+CAV-1 ${ }^{\text {WT }}$

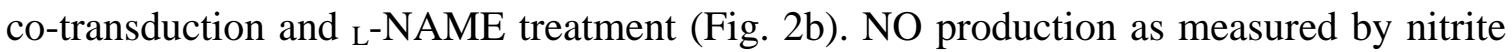
accumulation using the Griess assay (Fig. 2c) was increased in the eNOS-GFP and eNOS-GFP+CAV-1 ${ }^{\mathrm{F92A}}$ transduced cells and was reduced with ${ }_{\mathrm{L}}-\mathrm{NAME}$ treatment. NO production would appear to correlate with the phosphorylation status of eNOS (Fig. 2b and 2c). Furthermore, the expression of protein kinase B (AKT) which is a downstream target of NO was markedly increased in eNOS-GFP and CAV-1 ${ }^{\mathrm{F} 92 \mathrm{~A}}$ co-transduced cells (BMSC $^{\text {eNOS-GFP+CAV-1F92A }}$ ) again demonstrating a relationship with enhanced phosphorylation of eNOS (Fig. 2b). In addition, the western blot analysis showed expression of caveolin-1 in all cells demonstrating the presence of both endogenous

This article is protected by copyright. All rights reserved. 
CAV-1 and increased exogenous protein resulting from transgene overexpression in cells with either CAV-1 ${ }^{\mathrm{WT}}$ or CAV-1 ${ }^{\mathrm{F} 92 \mathrm{~A}}$ lentivectors (Fig. 2b).

\section{Nitric oxide promotes in vitro capillary formation}

The ability of the eNOS-GFP and CAV-1 ${ }^{\mathrm{F} 92 \mathrm{~A}}$ lentiviral transduced cells to produce in vitro capillary like structures was assessed. Only BMSC BNOS-GFP+CAV-1F92A $^{\text {and }}$ BMSC $^{\text {eNOS-GFP }}$ transduced cells formed capillary like structures (Fig. 2d). This in vitro capillary tubule formation was significantly impaired by BMSC ${ }^{\text {eNOS-GFP+CAV-1WT }}$ cells suggesting over-expression of CAV-1 ${ }^{\mathrm{WT}}$ inhibits NO production. Inhibition of eNOS activity with $2 \mathrm{mM}_{\mathrm{L}}$-NAME treatment of co-transduced BMSC ${ }^{\text {eNOS-GFP+CAV-1F92A }}$ cells also inhibited capillary tubule formation (Fig. 2d).

Nitric Oxide promotes BMSCs commitment towards an endothelial linage. To assess whether the eNOS-GFP fusion construct could induce endothelial specific gene expression, Pecam-1 and VE-cadherin gene expression was assessed by RT-qPCR. A significant increase in Pecam-1 (Fig. 2e) and VE-cadherin (Fig. 2f) expression in BMSC $^{\text {eNOS-GFP }}$ transduced cells was observed compared to BMSC ${ }^{\text {GFP }}$, and un-transduced cells. Compared with eNOS-GFP transduced cells alone, Pecam-1 (Fig. 2e) and VEcadherin (Fig. 2f) mRNA expression was significantly increased in the co-transduced

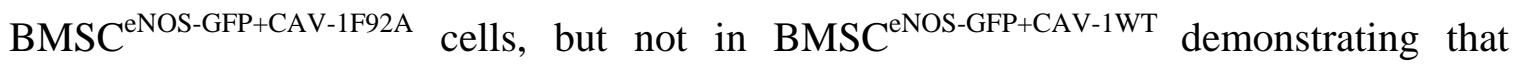
increased levels of $\mathrm{NO}$ associated with the $\mathrm{CAV}-1^{\mathrm{F} 2 \mathrm{~A}}$ protein can further enhance Pecam-1 and VE-cadherin expression whilst CAV-1 ${ }^{\mathrm{WT}}$ has an inhibitory effect. The role of NO in mediating Pecam-1 and VE-cadherin expression was highlighted further by

This article is protected by copyright. All rights reserved. 
treatment of BMSC ${ }^{\text {eNOS-GFP+CAV-1F92A }}$ with $2 \mathrm{mM}_{\mathrm{L}}$-NAME which resulted in reduced Pecam-1 (Fig. 2e) and VE-cadherin (Fig. 2f) expression.

Nitric oxide promotes angiogenic responsive gene expression.

Gene expression of angiogenic markers was assessed in lentiviral transduced cells. Expression of VEGF-A (Fig. 2g) and FGF2 (Fig. 2h) and their corresponding receptors PDGFRa (Fig. 2i) and FGFR2 (Fig. 2k) were increased in BMSC ${ }^{\text {eNOS-GFP }}$ cells and expression was further increased in BMSC BNOS-GFP+CAV-1F92A $^{\text {cells suggesting that }}$ increased levels of eNOS mediated NO may promote expression of angiogenic responsive genes. This was further supported by demonstrating that these gene expression profiles were abrogated in BMSC ${ }^{\text {eNOS-GFP+CAV-1WT }}$ and in BMSC ${ }^{\text {eNOS-GFP+CAV-1F92A }}$ treated

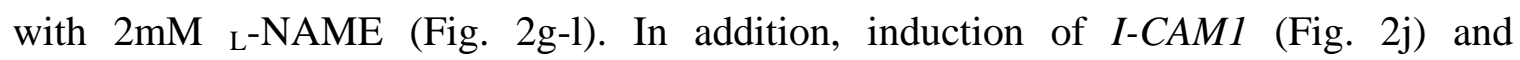
KDR1/VEGFR2 (Fig. 2l) gene expression was also increased in BMSC ${ }^{\text {eNOS-GFP }}$ and further increased in BMSC ${ }^{\text {eNOS-GFP+CAVF92A }}$ (Fig. 2j and 2l), whilst I-CAM1 (Fig. 2j) and KDR1/VEGFR2 (Fig. 2l) expression were significantly decreased in BMSC ${ }^{\text {eNOS-GFP+CAV- }}$

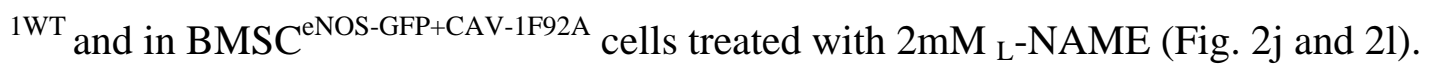

Activity of a Flt1 reporter and Flt1 gene expression in transduced rBMSCs

To further validate induction of endothelial differentiation by NO, an endothelial reporter system was developed, which is specifically activated in endothelial lineage committed cells. This reporter system consists of the Flt1 promoter upstream to the enhanced green fluorescence protein (eGFP) (Fig. 3a). To validate promoter specificity, a lentiviral vector expressing the Flt1-eGFP was used to transduce human microvascular endothelial cells (HMECs). After 5 days in growth medium transduced HMECs were positive for GFP expression (Fig. 3b). Flt1-eGFP reporter transduced rBMSCs were then co-transduced

This article is protected by copyright. All rights reserved. 
with lentiviral vectors expressing eNOS (without GFP fusion; pWPT-eNOS, supplementary table 1 ), eNOS $+\mathrm{CAV}-1^{\mathrm{WT}}$, eNOS $+\mathrm{CAV}-1^{\mathrm{F} 92 \mathrm{~A}}, \mathrm{CAV}-1^{\mathrm{WT}}$, and $\mathrm{CAV}$ $1^{\mathrm{F} 92 \mathrm{~A}}$. After 5 days post transduction, GFP expression was only seen in eNOS and, eNOS+CAV-1 ${ }^{\text {F92A }}$ transduced cells and which also appeared higher in eNOS+CAV-1 ${ }^{\text {F92A }}$ transduced cells (Fig. 3c). In addition to the Flt1-eGFP reporter expression data, gene expression analysis also confirmed the induction of endogenous Flt1 gene expression in $\mathrm{rBMSC}^{\mathrm{eNOS+CAV}-1 \mathrm{Fg} 2 \mathrm{~A}}$ and $\mathrm{rBMSC}^{\mathrm{eNOS}}$ (Fig. 3d) and this was significantly reduced in

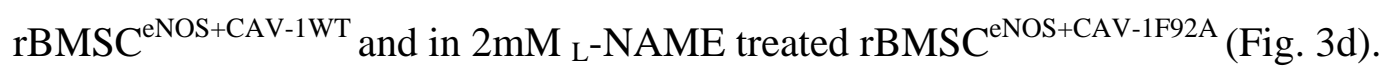

Nitric Oxide signalling promotes endothelial CD31 expression

To quantify the endothelial differentiation efficiency in BMSCs, flowcytometry analysis was employed using a PE conjugated CD31 antibody. Genetic modification of rBMSCs with eNOS and eNOS $+\mathrm{CAV}-1^{\mathrm{F} 92 \mathrm{~A}}$ increased the number of CD31 positive cells to approximately $9.8 \%$ and $16.2 \%$ respectively (Fig. 4). To confirm whether this increased endothelial differentiation was eNOS mediated, $\mathrm{rBMSCs}^{\text {eNOS+CAV-1F92A }}$ cells were treated with $2 \mathrm{mM}_{\mathrm{L}}$-NAME which resulted in a reduction of CD31 positive cells to undetectable levels as seen in untransduced cells. Furthermore, treatment of rBMSCs with $10 \mu \mathrm{M}$ NO donor (NONOate, $10 \mu \mathrm{M}$ ) resulted in approximately 9\% CD31 highlighting the potential for use of NO donors in the differentiation of BMSCs to endothelial cells.

\section{Nitric oxide induces an arterial specific endothelial cell transcriptional profile}

To determine the endothelial subtype generated through NO signalling, the gene expression profiles of arterial specific transcription factors in which Notch signalling plays a major role was analyzed by RT-qPCR. Expression of Dll4, and Notch1, upstream

This article is protected by copyright. All rights reserved. 
mediators of Notch signalling, and Hey2, a downstream effector of Notch signalling were significantly up regulated in rBMSC $^{\text {eNOS-GFP }}$ and this was further increased in rBMSC $^{\text {eNOS-GFP+CAV-1F92A }}$ cells (Fig. 5a). Treatment with 2mM L-NAME and overexpression of eNOS-GFP and CAV-1 ${ }^{\mathrm{WT}}$ in rBMSCs (rBMSC ${ }^{\text {eNOS-GFP+CAV-1WT }}$ ) resulted in a significant reduction of Dll4, Notch 1 and Hey2 expression (Fig. 5a). The expression profiles for the venous specific master transcription factor orphan nuclear receptor chicken ovalbumin upstream promoter-transcription factor II (COUP-TFII) and a lymphatic specific transcription factor prospero homeobox protein 1 (Prox1) were also assessed. Interestingly, both COUP-TFII (Fig. 5b) and Prox1 (Fig. 5c) mRNA expression was decreased in rBMSC ${ }^{\text {eNOS-GFP }}$ and further down regulated in rBMSC ${ }^{\text {eNOS-GFP+CAV-1F92A }}$. In contrast, this reduced expression of both COUP-TFII and Prox1 was not seen in rBMSC $^{\text {eNOS-GFP+CAV-1WT }}$ and ${ }_{\text {-NAME treated rBMSC }}$ eNOS-GFP+CAV-1F92A $^{\text {cNempared to }}$ rBMSC $^{\text {eNOS-GFP+CAV-1F92A }}$ suggesting that increased levels of NO may inhibit expression of venous and lymphatic specific master transcription factors.

Nitric oxide promotes endothelial differentiation of rBMSCs through canonical Wnt signalling.

To examine the role of canonical Wnt signalling during NO mediated endothelial differentiation, expression of Wnt3a was assessed by RT-qPCR (Fig. 6a) and was up regulated in BBMSC $^{\text {eNOS-GFP }}$ and significantly further increased in $\mathrm{rBMSC}^{\text {eNOS-GFP+CAV- }}$ ${ }^{1 F 92 A}$ (Fig. 6a). Treatment with 2 mM L-NAME down regulated Wht3a expression in rBMSC $^{\text {eNOS-GFP+CAV-1F92A }}$ (Fig. 6a), indicating that NO is a modulatory factor of canonical Wnt3a expression in rBMSCs. Furthermore, western blot analysis revealed increased expression of $\beta$-catenin in rBMSC $^{\text {eNOS-GFP }}$ and interestingly higher expression was observed in rBMSC $\mathrm{eNOS-GFP+CAV-1F92A}^{\text {(Fig. 6c). Treatment of rBMSC }}$ eNOS-GFP+CAV-1F92A $^{\text {. }}$

This article is protected by copyright. All rights reserved. 
with $2 \mathrm{mM}_{\mathrm{L}}$-NAME resulted in a loss of $\beta$-catenin protein expression (Fig. 6c). To further analyse the relationship between NO-induced endothelial differentiation and Wnt3a signalling, rBMSC ${ }^{\text {eNOS-GFP+CAV-1F92A }}$ were treated with $20 \mathrm{ng} / \mathrm{ml}$ of the Wnt signalling inhibitor, Dickkopf-related protein 1 (Dkk-1). Dkk-1 treatment resulted in a significant down regulation of the endothelial specific marker Pecam-1 (Fig. 6b.) compared to untreated rBMSC $\mathrm{CNOS-GFP+CAVF92A}^{\text {. }}$

\section{Nitric oxide inhibits specific DNA methylase expression and demethylates the endothelial Flt1 promoter}

To determine if NO mediated endothelial differentiation of rBMSCs involves epigenetic modification, the expression of specific DNA methyltransferases Dnmt1, Dnmt3a and Dnmt3b was assessed. RT-qPCR analysis revealed that Dnmt1 (Fig. 7a) was significantly down regulated in rBMSC ${ }^{\text {eNOS-GFP+CAV-1F92A }}$ but was restored to basal levels with $2 \mathrm{mM}_{\mathrm{L}^{-}}$ NAME treatment in rBMSC ${ }^{\text {eNOS-GFP+CAV-1F92A }}$ and in rBMSC ${ }^{\text {eNOS-GFP+CAV-1WT }}$. The effect of NO appeared to be specific for Dnmt1 as no significant difference in Dnmt3a and Dnmt3b expression was observed in NO producing cells (Fig. 7a). To further demonstrate an association between epigenetic modification and NO, bisulphite sequencing analysis was performed to analyze the methylation level of the endothelial specific Flt1 promoter region. We analysed $6 \mathrm{CpG}$ sites in the promoter and found that the CpG-rich promoter region was hyper methylated in rBMSCs and interestingly, was significantly hypomethylated in rBMSCs ${ }^{\text {eNOS+CAV-1F92A }}$ (Fig. 7b), suggesting that enhanced level of NO can demethylate endothelial specific Flt1 promoter to facilitate endothelial differentiation.

This article is protected by copyright. All rights reserved. 


\section{In vivo blood vessel formation with Nitric Oxide producing rat BMSCs}

The vasculogenic potential of the lentiviral vector transduced rBMSCs was evaluated using the rat sub-cutaneous transplant model (Fig. 8a). Staining with hematoxylin and eosin (H\&E) (Fig. 8b) and lectin (Fig. 8c) demonstrated that vascularization of cell laden scaffolds was evident at 7 days post transplantation and erythrocytes also could be observed in newly formed blood vessels suggesting that those vessels may have been associated with the host circulation system (Figs. 8b \& 8c). However, when blood vessel formation was quantified there was no significant difference seen among the groups (Supplementary figure 2). To investigate whether the genetically engineered cells survived within the scaffolds and formed blood vessels in vivo, tissues were stained with a GFP specific antibody to identify transplanted BMSCs expressing GFP. GFP positive cells were found in the scaffold after 7 days transplantation (Fig. 8d) and interestingly some of the blood vessels were shown association with GFP positive cells in eNOS-GFP and eNOS-GFP+CAV-1 ${ }^{\mathrm{F} 92 \mathrm{~A}}$ treatment groups (white arrow in Fig. 8d), suggesting that nitric oxide producing cells remain viable and can form blood vessels in vivo.

\section{Discussion}

The major finding of the present study is the demonstration that genetic engineering of BMSCS to recreate a functional eNOS-NO signalling pathway in rat BMSCs can be successfully employed to generate endothelial-like cells. This approach has been demonstrated through a series of in vitro experiments, whereby lentiviral vector overexpression of eNOS together with a mutant CAV-1 (CAV-1 $\left.{ }^{\mathrm{F} 2 \mathrm{~A}}\right)$ enhanced eNOS phosphorylation and NO production resulting in upregulation of a range of endothelial cell makers and an in vivo ability to form neovessels.

This article is protected by copyright. All rights reserved. 
It has been shown that iNOS and nNOS are expressed in BMSCs but eNOS is absent (Gomes, Rangel, Premer, \& Dulce, 2013) and inhibition of iNOS and nNOS has been shown to promote vasculogenesis whereas inhibition of eNOS in human umbilical vein endothelial cells has been shown to attenuate it. This highlights the opposing roles of NOS isoforms in terms of vasculogenesis, in which eNOS can promote whilst iNOS and nNOS inhibit the generation of blood vessels. eNOS phosphorylation at Ser-1177 is an important step in the functioning of eNOS-NO signaling (Sessa, 2004). In the present study, we found increased eNOS phosphorylation status at Ser-1177 and Akt expression in rat BMSCs co-transduced with eNOS and CAV-1 ${ }^{\mathrm{F} 92 \mathrm{~A}}$. This may suggest a positive feedback mechanism of NO in which increased levels of NO synthesis through eNOS and $\mathrm{CAV}-1^{\mathrm{F}}{ }^{\mathrm{F} A}$ interaction induced Akt expression as a downstream target of NO (Kawasaki, Hsieh, Sun, \& S., 2003) and increased expression of Akt may in turn promote eNOS phosphorylation as a positive feedback loop (Sessa, 2004). However, this mechanism remains to be explored in terms of further understanding the increased eNOS phosphorylation associated with the $\mathrm{CAV}-1^{\mathrm{F} 92 \mathrm{~A}}$ protein. $\mathrm{CAV}-1$ has been shown to be an endogenous negative regulator of eNOS and can therefore attenuate eNOS-mediated NO synthesis (P. Bernatchez et al., 2011; P. N. Bernatchez, Bauer, Yu, \& Prendergast, 2005). Of note, CAV-1 is naturally expressed in MSCs (Baker, Shon, \& Tuan, 2015) and therefore can reduce eNOS activation and subsequent NO production. Overexpression of $\mathrm{CAV}-1^{\mathrm{F}}{ }^{\mathrm{F} A}$ with eNOS resulted in an increased level of NO synthesis, which is attributed to the interaction of the F92A mutated CAV-1 with the eNOS reductase domain, and this interaction may increase electron mobility due to the loss of aromatic rings in $\mathrm{CAV}-1^{\mathrm{F} 2 \mathrm{~A}}$

This article is protected by copyright. All rights reserved. 
and therefore activate eNOS by electron mobilization through the reductase domain (P. N. Bernatchez et al., 2005).

During vascular development, multipotent endothelial progenitors initiate angiogenic sprouting to form a mature blood vessels composed of a network of arteries and veins, and it has been shown that development of endothelial cell types including arterial, venous and lymphatic specification is tightly regulated by intrinsic genetic programs (Nolan, Ginsberg, \& Israely, 2013; Swift \& Weinstein, 2009). Notch signalling induces arterial specification and genetic deletion of Notch pathway components has been shown to inhibit arterial development (Kokubo, Miyagawa-Tomita, Nakazawa, \& Saga, 2005; Krebs, Shutter, Tanigaki, \& Honjo, 2004). Activation of the Notch pathway can induce arterial-specific ephrinB2 and block venous-specific EphB4 expression in arterial endothelial cells, whereas an opposite genetic program is activated in venous endothelial cells through COUP-TFII (chicken ovalbumin upstream promoter transcription factor 2) (Aranguren, Beerens, \& Coppiello, 2013). COUP-TFII, also known as NR2F2 (nuclear receptor subfamily 2, group $\mathrm{F}$, member 2), is the master transcription factor in venous specification and has been shown to suppress Notch signalling to direct endothelial differentiation towards venous identity (You, Lin, Lee, \& DeMayo, 2005). On the other hand, it has been demonstrated that a sub set of venous endothelial cells start to express lymphatic specific master transcription factor Prox1 directing that cell population towards lymphatic identity (Francois, Caprini, Hosking, \& Orsenigo, 2008). In the present study, we found that eNOS-NO signalling inhibits venous and lymphatic specific master transcription factors COUP-TFII and Prox1, and interestingly increased arterial specifying Notch signaling associated components, including Notch component Dll4,

This article is protected by copyright. All rights reserved. 
Notch1 and downstream Notch target Hey2. Furthermore, Corada et al have shown that Wnt $/ \beta$-catenin signaling acts upstream to the Notch signaling and that $\beta$-catenin can increase Notch signaling both in vitro and in vivo (Corada, Nyqvist, Orsenigo, \& Caprini, 2010). Thus, it is possible that eNOS-NO signaling may up-regulate $\mathrm{Wnt} / \beta$-catenin signaling to direct BMSC commitment towards arterial endothelial identity by inhibiting venous-specific EphB4 and lymphatic master regulator Prox1 through inhibiting COUPTFII since expression of venous-specific COUP-TFII is required for venous specification (Aranguren et al., 2013) and initiation of Prox1 expression by direct interaction (Yamazaki, Yoshimatsu, Morishita, \& Miyazono, 2009).

Canonical Wnt3a has been shown to promote angiogenesis by promoting VEGF signaling (Gore, Swift, Cha, \& Lo, 2011). In the activated canonical Wnt pathway, Wnt3a associates with cell surface frizzled receptors, which resulted in $\beta$-catenin stabilization in the cytoplasm by inhibiting its phosphorylation and promote subsequent translocation into the nucleus (Voloshanenko, Erdmann, Dubash, \& Augustin, 2013). In the nucleus, $\beta$-catenin associates with TCF/LEF region to initiate the transcription of angiogenic responsive genes such as IL-8 (Masckauchan, Shawber, Funahashi, \& Li, 2005). Increased levels of NO have been shown to induce Wnt/ $\beta$-catenin signaling by inhibiting Dkk-1 (Du, Zhang, \& Liu, 2013) and the observed induction of endothelial differentiation by rat BMSCs transduced with eNOS and CAV-1 ${ }^{\mathrm{F} 2 \mathrm{~A}}$ (Figures 2-4) in this study may link with induction of Wnt/ $\beta$-catenin signalling (Figure 6). Taken together, it is plausible that NO may stabilize $\beta$-catenin for nuclear translocation through activation of Wnt3a-mediated canonical Wnt signaling and ultimately result in increased transcription of endothelial-specific genes.

This article is protected by copyright. All rights reserved. 
DNA methyltransferases such as Dnmt1 and Dnmt3a are DNA modifying enzymes which can add a methyl group to cytosine residues primarily in promoter regions and this is associated with inhibition of neighboring gene transcription (Liu, Wu, Ji, Stelzer, \& A., 2016). Therefore, DNA methyltransferases are important components in the regulation of cellular differentiation especially their expression in human BMSCs has been shown to repress endothelial differentiation and siRNA mediated knockdown of Dnmt1 and Dnmt3a has been shown to promote arterial endothelial differentiation (Zhang, Wang, Zhang, \& Huang, 2016). Interestingly, methylation patterns of the eNOS promoter have been shown to be involved in endothelial cell identity, in which the eNOS promoter is demethylated in endothelial cells and methylated in smooth muscle cells (Y. Chan et al., 2004; Fish, Matouk, Rachlis, \& Lin, 2005). Furthermore, inhibition of DNA methylation by inhibiting Dnmt through 5'-aza-2'-deoxycytidine treatment in embryonic stem cells has been shown to promote endothelial differentiation (Banerjee \& Bacanamwo, 2010). Together, our findings may suggest that inhibition of Dnmt1 expression (Figure 7a) maybe as a result of increased levels of NO and subsequent demethylation of Flt1 promoter (Fig. 7b) which could attribute to increased endothelial differentiation of BMSCs.

Finally, in vivo transplantation of NO producing cells (rBMSC ${ }^{\mathrm{eNOS}}$ and $\mathrm{rBMSC}^{\mathrm{eNOS}+\mathrm{CAV}-}$ ${ }^{1 F 92 A}$ ) displayed blood vessel formation (Fig. 8) which was similar to the in vitro findings where enhanced endothelial differentiation was observed. Whilst the genetically modified BMSCs remained viable following sub-cutaneous transplantation, there was no significant increase in neovessel formation associated with this modification. Possible explanations for this in vitro and in vivo differences might be attributed to the use of an

This article is protected by copyright. All rights reserved. 
extracellular matrix such as matrigel in in vitro experiments and fibrin for in vivo transplantation. A previous study has shown that Matrigel can stimulate differentiation of MSCs towards an endothelial phenotype (Lozito, Taboas, Kuo, \& Tuan, 2009). Furthermore, Chung and colleagues have shown significant increase in angiogenic responsive gene expression, von Willebrand factor and VEGF in adipose derived MSCs when cultured on fibrin compared to normal MSCs (Chung, Rytlewski, Merchant, \& Dhada, 2015). Several other studies have also demonstrated that fibrin acts as a stimulator for angiogenic factors such as VEGF release (Morin \& Tranquillo, 2013; Shiose, Hata, Noda, \& Sassa, 2004).

In summary, the results of this study propose that a functioning eNOS-NO signaling pathway may modulate epigenetic regulation of chromatin by inhibiting the DNA methyltransferase Dnmt1, which may subsequently influence endothelial specific Flt1 promoter activation to induce endothelial differentiation. Furthermore, NO can also activate $\mathrm{Wnt} / \beta$-catenin signaling to promote downstream arterial endothelial-specific genes transcription (Figure 9). These findings provide a novel insight into the role of NO in lineage conversion of MSCs to endothelial-like cells through activation of Wnt/ $\beta$ catenin signalling pathway and modulating DNA methylation events. This may lead to the development of novel cell-based therapeutic approaches for vascular repair, in particular in vitro modification of MSCs to produce NO and for subsequent transplantation into damaged areas to improve vascularization and wound healing.

This article is protected by copyright. All rights reserved. 


\section{Declarations}

\section{Acknowledgements}

The authors wish to thank technical staff at the National Life Sciences Hub (Charles Sturt University) and at the O’Brien Institute Department, St Vincent’s Institute of Medical Research.

\section{Funding}

This work was supported by Stafford Fox Medical Research Foundation. N.B. is supported by the Australian Government International Post-Graduate Research Scholarship (IPRS), Australian Post-Graduate Award (APA) from Charles Sturt University and a Mackenzie Hummingbird Fellowship. The O’Brien Institute Department and St Vincent's Institute of Medical Research receive Operational Infrastructure Support from the Victorian State Government's Department of Innovation, Industry and Regional Development.

\section{Availability of data and materials}

The datasets used and/or analysed during the current study are available from the corresponding author on reasonable request. All lentiviral vector constructs used in this are available on reasonable request.

This article is protected by copyright. All rights reserved. 


\section{Authors' contributions}

NB and PS designed and performed the research, analysed data and wrote the manuscript.

AK, GM, LW, SYL performed research and analysed the data All authors read and approved the final manuscript.

\section{Ethics approval and consent to participate}

Experimental procedures were approved by the Animal Ethics Committee of St.

Vincent’s Hospital (Melbourne) and were conducted in accordance with the Australian National Health and Medical Research Council guidelines for the care and maintenance of animals

\section{Competing interests}

The authors declare that they have no competing interest

\section{References}

Aranguren, X. L., Beerens, M., \& Coppiello, G. (2013). COUP-TFII orchestrates venous and lymphatic endothelial identity by homo-or hetero-dimerisation with PROX1. J Cell Sci, 126, 1164-1175.

Baker, N., Shon, J., \& Tuan, R. S. (2015). Promotion of human mesenchymal stem cell osteogenesis by PI3-kinase/Akt signaling and the influence of caveolin1/cholesterol homeostasis. Stem Cells Res Ther 238, 6 SRC - GoogleScholar.

Bandara, N., Gurusinghe, S., Lim, S. Y., Chen, H., Chen, S., Wang, D., . . . Strappe, P. (2016). Molecular control of nitric oxide synthesis through eNOS and caveolin-1 interaction regulates osteogenic differentiation of adipose-derived stem cells by modulation of Wnt/beta-catenin signaling. Stem Cell Res Ther, 7(1), 182. doi:10.1186/s13287-016-0442-9

Banerjee, S., \& Bacanamwo, M. (2010). DNA methyltransferase inhibition induces mouse embryonic stem cell differentiation into endothelial cells. Exp Cell Res, 316, 172-180.

This article is protected by copyright. All rights reserved. 
Bernatchez, P., Sharma, A., Bauer, P. M., Marin, E., \& Sessa, W. C. (2011). A noninhibitory mutant of the caveolin-1 scaffolding domain enhances eNOSderived NO synthesis and vasodilation in mice. J Clin Invest, 121(9), 3747-3755. doi:10.1172/JCI44778

Bernatchez, P. N., Bauer, P. M., Yu, J., \& Prendergast, J. S. (2005). Dissecting the molecular control of endothelial NO synthase by caveolin-1 using cell-permeable peptides. Proc Natl Acad Sci U S A, 102, 761-766.

Boomsma, R. A., \& Geenen, D. L. (2012). Mesenchymal stem cells secrete multiple cytokines that promote angiogenesis and have contrasting effects on chemotaxis and apoptosis. PLoS One, 7(4), e35685. doi:10.1371/journal.pone.0035685

Bronckaers, A., Hilkens, P., Martens, W., Gervois, P., Ratajczak, J., Struys, T., \& Lambrichts, I. (2014). Mesenchymal stem/stromal cells as a pharmacological and therapeutic approach to accelerate angiogenesis. Pharmacol Ther, 143(2), 181196. doi:10.1016/j.pharmthera.2014.02.013

Cao, N., Huang, Y., Zheng, J., Spencer, C. I., Zhang, Y., Fu, J. D., . . . Ding, S. (2016). Conversion of human fibroblasts into functional cardiomyocytes by small molecules. Science, 352(6290), 1216-1220. doi:10.1126/science.aaf1502

Chan, E. C., Kuo, S. M., Kong, A. M., Morrison, W. A., Dusting, G. J., Mitchell, G. M., . . . Liu, G. S. (2016). Three Dimensional Collagen Scaffold Promotes Intrinsic Vascularisation for Tissue Engineering Applications. PLoS One, 11(2), e0149799. doi:10.1371/journal.pone.0149799

Chan, Y., Fish, J. E., Abreo, C., Lin, S., Steer, B. M., \& Marsden, P. A. (2004). D' \& The cell-specific expression of endothelial nitric-oxide synthase: a role for DNA methylation. J Biol Chem, 279 SRC - GoogleScholar, 35087-35100.

Chung, E., Rytlewski, J. A., Merchant, A. G., \& Dhada, K. S. (2015). Fibrin-based 3D matrices induce angiogenic behavior of adipose-derived stem cells. Acta Biomater, 17, 78-88.

Corada, M., Nyqvist, D., Orsenigo, F., \& Caprini, A. (2010). The Wnt/beta-catenin pathway modulates vascular remodeling and specification by upregulating Dll4/Notch signaling. Dev Cell, 18, 938-949.

Daniel Becker, P. L., Peter Ebert, Christoph Bock, Thomas Lengauer and Jo, Walter. (2014). BiQ Analyzer HiMod: an interactive software tool for high-throughput locus-specific analysis of 5-methylcytosine and its oxidized derivatives. Nucleic Acids Research, 42, W501-W507. doi:10.1093/nar/gku457

Du, Q., Zhang, X., \& Liu, Q. (2013). Nitric oxide production upregulates Wnt/ $\beta$-catenin signaling by inhibiting Dickkopf-1. Cancer Res, 73, 6526-6537.

This article is protected by copyright. All rights reserved. 
Fish, J. E., Matouk, C. C., Rachlis, A., \& Lin, S. (2005). The expression of endothelial nitric-oxide synthase is controlled by a cell-specific histone code. J Biol Chem, 280, 24824-24838.

Francois, M., Caprini, A., Hosking, B., \& Orsenigo, F. (2008). Sox18 induces development of the lymphatic vasculature in mice. Nature, 456, 643-647.

Gomes, S. A., Rangel, E. B., Premer, C., \& Dulce, R. A. (2013). S-nitrosoglutathione reductase (GSNOR) enhances vasculogenesis by mesenchymal stem cells. Proc Natl Acad Sci, 110 SRC - GoogleScholar, 2834-2839.

Gore, A. V., Swift, M. R., Cha, Y. R., \& Lo, B. (2011). Rspo1/Wnt signaling promotes angiogenesis via Vegfc/Vegfr3. Development. 138 SRC - GoogleScholar, 48754886.

Hou, L., Kim, J. J., Woo, Y. J., \& Huang, N. F. (2016). Stem cell-based therapies to promote angiogenesis in ischemic cardiovascular disease. Am J Physiol Heart Circ Physiol, 310(4), H455-465. doi:10.1152/ajpheart.00726.2015

Hsiao, S. T., Asgari, A., Lokmic, Z., Sinclair, R., Dusting, G. J., Lim, S. Y., \& Dilley, R. J. (2012). Comparative analysis of paracrine factor expression in human adult mesenchymal stem cells derived from bone marrow, adipose, and dermal tissue. Stem Cells Dev, 21(12), 2189-2203. doi:10.1089/scd.2011.0674

Ignarro, L. J., Buga, G. M., Wood, K. S., Byrns, R. E., \& Chaudhuri, G. (1987). Endothelium-derived relaxing factor produced and released from artery and vein is nitric oxide. Proc Natl Acad Sci U S A, 84(24), 9265-9269.

Iwakiri, Y., Satoh, A., Chatterjee, S., Toomre, D. K., Chalouni, C. M., Fulton, D., . . . Sessa, W. C. (2006). Nitric oxide synthase generates nitric oxide locally to regulate compartmentalized protein S-nitrosylation and protein trafficking. Proc Natl Acad Sci U S A, 103(52), 19777-19782. doi:10.1073/pnas.0605907103

Kawasaki, K., Hsieh, C. M., Sun, J., \& S., R. (2003). Smith Activation of the phosphatidylinositol 3-kinase/protein kinase Akt pathway mediates nitric oxideinduced endothelial cell migration and angiogenesis. Mol Cell Biol, 23, 57265737.

Kokubo, H., Miyagawa-Tomita, S., Nakazawa, M., \& Saga, Y. (2005). Mouse hesr1 and hesr2 genes are redundantly required to mediate Notch signaling in the developing cardiovascular system. Dev Biol, 278, 301-309.

Krebs, L. T., Shutter, J. R., Tanigaki, K., \& Honjo, T. (2004). Haploinsufficient lethality and formation of arteriovenous malformations in Notch pathway mutants. Genes Dev, 18, 2469-2473.

Lian, X., Bao, X., Al-Ahmad, A., Liu, J., Wu, Y., Dong, W., . . Palecek, S. P. (2014). Efficient differentiation of human pluripotent stem cells to endothelial progenitors

This article is protected by copyright. All rights reserved. 
via small-molecule activation of WNT signaling. Stem Cell Reports, 3(5), 804816. doi:10.1016/j.stemcr.2014.09.005

Lian, X., Hsiao, C., Wilson, G., Zhu, K., Hazeltine, L. B., Azarin, S. M., .. . Palecek, S. P. (2012). Robust cardiomyocyte differentiation from human pluripotent stem cells via temporal modulation of canonical Wnt signaling. Proc Natl Acad Sci U S A, 109(27), E1848-1857. doi:10.1073/pnas.1200250109

Liu, X. S., Wu, H., Ji, X., Stelzer, Y., \& A., D. N. (2016). Editing in the Mammalian Genome. Cell e17, 167 SRC - GoogleScholar, 233-247.

Lozito, T. P., Taboas, J. M., Kuo, C. K., \& Tuan, R. S. (2009). Mesenchymal stem cell modification of endothelial matrix regulates their vascular differentiation. $J$ Cell Biochem, 107, 706-713.

Lu, Y., Xiong, Y., Huo, Y., Han, J., Yang, X., Zhang, R., . . Luo, J. (2011). Grb-2associated binder 1 (Gab1) regulates postnatal ischemic and VEGF-induced angiogenesis through the protein kinase A-endothelial NOS pathway. Proc Natl Acad Sci U S A, 108(7), 2957-2962. doi:10.1073/pnas.1009395108

Masckauchan, T. N., Shawber, C. J., Funahashi, Y., \& Li, C. M. (2005). Wnt/beta-catenin signaling induces proliferation, survival and interleukin-8 in human endothelial cells. Angiogenesis, 8, 43-51.

McGinley, L., McMahon, J., Strappe, P., Barry, F., Murphy, M., O'Toole, D., \& O'Brien, T. (2011). Lentiviral vector mediated modification of mesenchymal stem cells \& enhanced survival in an in vitro model of ischaemia. Stem Cell Res Ther, 2(2).

Morin, K. T., \& Tranquillo, R. T. (2013). In-vitro models of angiogenesis and vasculogenesis in fibrin gel. Exp Cell Res, 319, 2409-2417.

Mujoo, K., Krumenacker, J. S., \& Murad, F. (2011). Nitric oxide-cyclic GMP signaling in stem cell differentiation. Free Radic Biol Med, 51(12), 2150-2157. doi:10.1016/j.freeradbiomed.2011.09.037

Nolan, D. J., Ginsberg, M., \& Israely, E. (2013). Molecular signatures of tissue-specific microvascular endothelial cell heterogeneity in organ maintenance and regeneration. Dev Cell, 26, 204-219.

Patel, D. M., Shah, J., \& Srivastava, A. S. (2013). Therapeutic potential of mesenchymal stem cells in regenerative medicine. Stem Cells Int, 2013, 496218. doi:10.1155/2013/496218

Rennie, M. Y., Rahman, A., Whiteley, K. J., Sled, J. G., \& Adamson, S. L. (2015). Sitespecific increases in utero- and fetoplacental arterial vascular resistance in eNOSdeficient mice due to impaired arterial enlargement. Biol Reprod, 92(2), 48. doi:10.1095/biolreprod.114.123968

This article is protected by copyright. All rights reserved. 
Sessa, W. C. (2004). eNOS at a glance. J Cell Sci, 117, 2427-2429.

Shiose, S., Hata, Y., Noda, Y., \& Sassa, Y. (2004). Fibrinogen stimulates in-vitro angiogenesis by choroidal endothelial cells via autocrine VEGF. Graefes Arch Clin Exp Ophthalmol, 242, 777-783.

Sumi, T., Tsuneyoshi, N., Nakatsuji, N., \& Suemori, H. (2008). Defining early lineage specification of human embryonic stem cells by the orchestrated balance of canonical Wnt/beta-catenin, Activin/Nodal and BMP signaling. Development, 135(17), 2969-2979. doi:10.1242/dev.021121

Swift, M. R., \& Weinstein, B. M. (2009). Arterial-venous specification during development. Circ Res, 104, 576-588.

Tam, P. P., \& Loebel, D. A. (2007). Gene function in mouse embryogenesis: get set for gastrulation. Nat Rev Genet, 8(5), 368-381. doi:10.1038/nrg2084

Thomas, D. D. (2015). Breathing new life into nitric oxide signaling: a brief overview of the interplay between oxygen and nitric oxide. Redox Biol, 5 SRC GoogleScholar, 225-233.

Tiscornia, G., Singer, O., \& Verma, I. M. (2006). Production and purification of lentiviral vectors. Nat Protoc, 1(1), 241-245. doi:10.1038/nprot.2006.37

Vaughn, M. W., Kuo, L., \& Liao, J. C. (1998). Effective diffusion distance of nitric oxide in the microcirculation. Am J Physiol, 274(5 Pt 2), H1705-1714.

Voloshanenko, O., Erdmann, G., Dubash, T. D., \& Augustin, I. (2013). Wnt secretion is required to maintain high levels of Wnt activity in colon cancer cells. Nat Commun 2610, 4 SRC - GoogleScholar.

Wang, Z., Liu, C. H., Sun, Y., Gong, Y., Favazza, T. L., Morss, P. C., . . . Chen, J. (2016). Pharmacologic Activation of Wnt Signaling by Lithium Normalizes Retinal Vasculature in a Murine Model of Familial Exudative Vitreoretinopathy. Am J Pathol, 186(10), 2588-2600. doi:10.1016/j.ajpath.2016.06.015

Xu, J., Du, Y., \& Deng, H. (2015). Direct lineage reprogramming: strategies, mechanisms, and applications. Cell Stem Cell, 16(2), 119-134. doi:10.1016/j.stem.2015.01.013

Yamazaki, T., Yoshimatsu, Y., Morishita, Y., \& Miyazono, K. (2009). COUP-TFII regulates the functions of Prox1 in lymphatic endothelial cells through direct interaction. Genes Cells, 14, 425-434.

Yang, P., Zhang, Y., Pang, J., Zhang, S., Yu, Q., He, L., . . Wang, C. Y. (2013). Loss of Jak2 impairs endothelial function by attenuating Raf-1/MEK1/Sp-1 signaling along with altered eNOS activities. Am J Pathol, 183(2), 617-625. doi:10.1016/j.ajpath.2013.04.007

This article is protected by copyright. All rights reserved. 
You, L. R., Lin, F. J., Lee, C. T., \& DeMayo, F. J. (2005). Suppression of Notch signalling by the COUP-TFII transcription factor regulates vein identity. Nature, 435, 98-104.

Zhang, R., Wang, N., Zhang, L. N., \& Huang, N. (2016). Knockdown of DNMT1 and DNMT3a Promotes the Angiogenesis of Human Mesenchymal Stem Cells Leading to Arterial Specific Differentiation. Stem Cells, 34 SRC - GoogleScholar, 1273-1283.

Zhang, Z., Nor, F., Oh, M., Cucco, C., Shi, S., \& Nor, J. E. (2016). Wnt/beta-Catenin Signaling Determines the Vasculogenic Fate of Postnatal Mesenchymal Stem Cells. Stem Cells, 34(6), 1576-1587. doi:10.1002/stem.2334

Figure 1. Functional characterization of the eNOS-GFP construct. (a), The eNOS cDNA sequence was PCR amplified and sub cloned into the pLVX-eGFP plasmid and ligation was confirmed by double digestion. (b), Lentiviral vectors expressing eNOS-GFP or GFP (negative control) were used to transduce rBMSCs and the expression of eNOS was confirmed by western blot analysis and (c), immunofluorescence microscopy with an eNOS specific antibody or visualization of GFP fluorescence. (d), significant nitric oxide production was seen in lenti (Lv)-eNOS-GFP transduced rBMSCs as measured by the Griess assay. $* p<0.05$ vs. compared with lenti (Lv)-GFP transduced cells and untransduced rBMSCs.

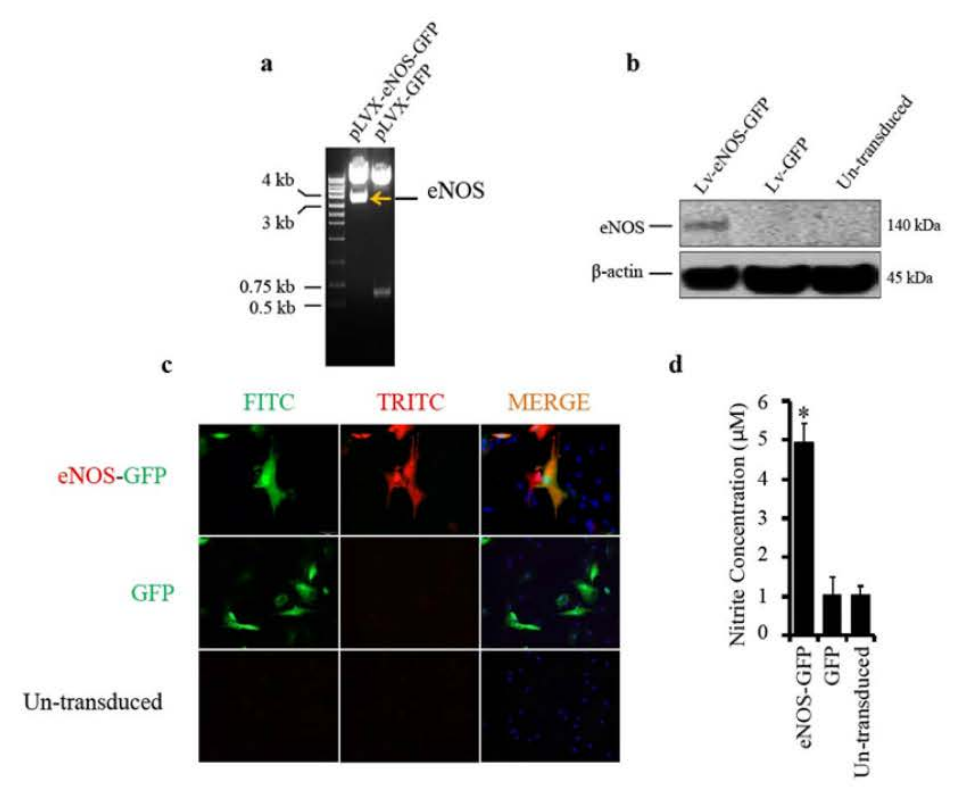

Figure 1

This article is protected by copyright. All rights reserved. 
Figure 2. Lentiviral vector mediated genetic engineering of rBMSCs and endothelial differentiation. (a), Schematic of lentiviral transduction strategy in which rBMSCs were transduced with eNOS-GFP and GFP separately and $72 \mathrm{~h}$ post transduction, GFP expressing cells were sorted and re-plated.

Following a further 6 days incubation in growth medium, the eNOS-GFP and the GFP cells were then re-transduced with lentiviral vectors expressing CAV-1WT or CAV-1F92A and incubated for a further $72 \mathrm{~h}$ and then subjected to downstream analysis. (b), Western blot analysis for expression of key proteins in the NO signalling pathway in transduced rBMSCs and control cells, showing upregulation of eNOS and specifically phosphorylated eNOS in LV-eNOS-GFP and LV-eNOS-GFP+CAV-1F92A cells together with upregulation of Akt. Expression of eNOS, phosphorylated eNOS and Akt were significantly reduced by L-NAME treatment (c), NO production in transduced cells and controls as measured by the Griess assay. (d), In vitro capillary tubule formation by lentiviral transduced and non-transduced control cells. Relative mRNA expression of endothelial-specific, (e) Pecam-1 and ( $f$ ) VE-cadherin and angiogenic responsive genes (g) Vegf-a (h) Fgf2 (i) Pdgfra and (j) Icam-1, (k), Fgfr2 and (I) Kdr1 were upregulated in eNOS-GFP and eNOS-GFP+CAV-1F92A transduced rBMSCs as assessed by quantitative real time PCR. $* p<0.05$ and $\# p<0.05$ vs. eNOS-GFP+CAV-1F92A (LNAME), eNOSGFP+ CAV-1WT, CAV-1WT, CAV-1F92A, GFP, and rBMSCs. Scale bars $=50 \mu \mathrm{m}$. Scale bars $=50 .(n=3)$

This article is protected by copyright. All rights reserved. 


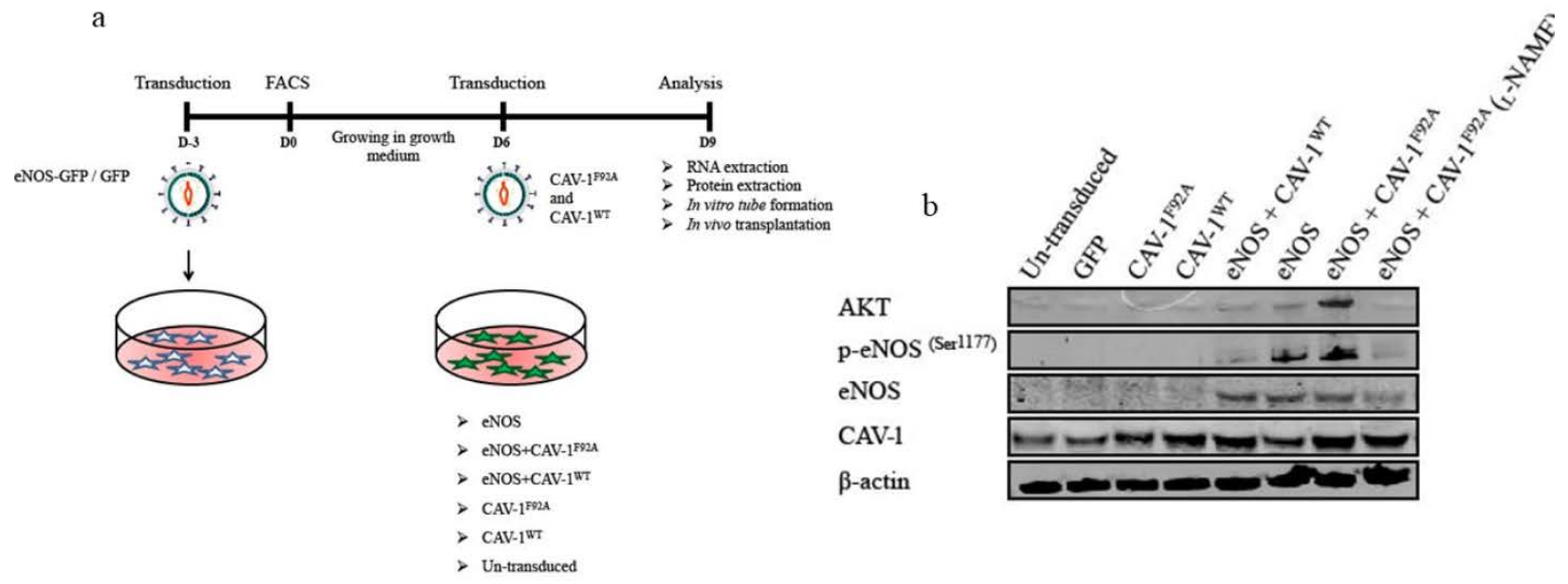

c

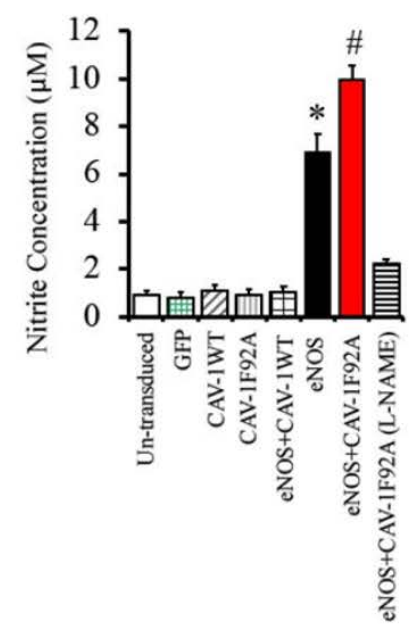

Figure 2
Fimura?

d
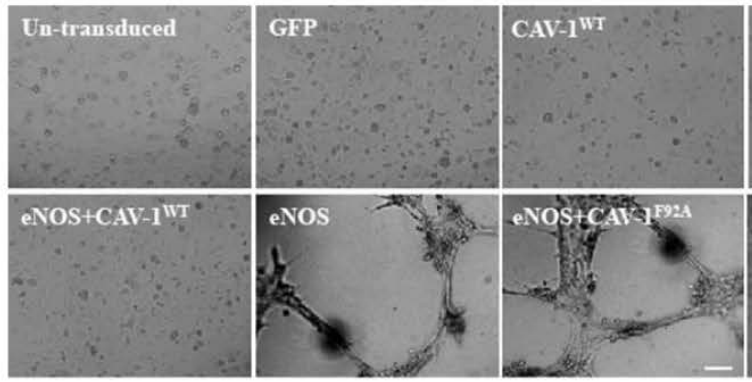

CAV-1 ${ }^{\text {F924 }}$

e

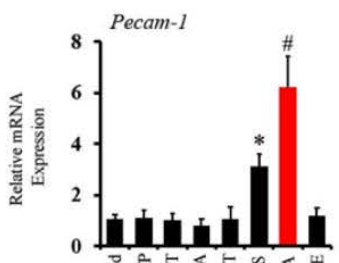

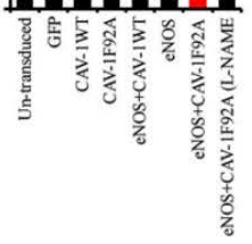

f 10, VE-cadherin

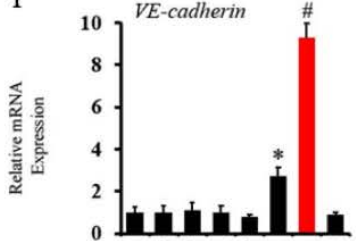

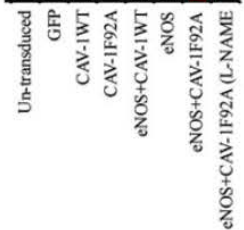

This article is protected by copyright. All rights reserved. 

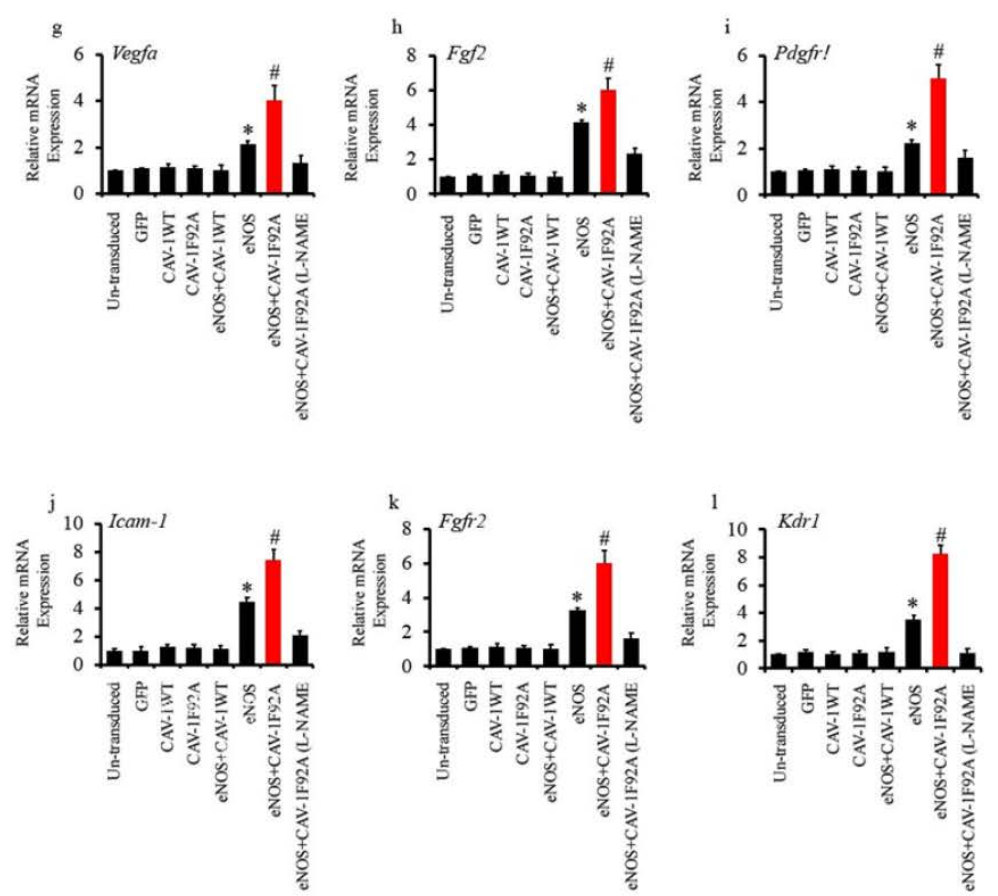

Figure 2

This article is protected by copyright. All rights reserved. 
Figure 3. Activity of an endothelial specific Flt1 promoter-GFP reporter construct during Nitric oxide mediated rBMSC differentiation. (a) Schematic of the Flt1-eGFP lentiviral reporter used to transduce rBMSCs. The construct contains 1049-bp of the human Flt1 promoter upstream of enhanced green fluorescent protein (eGFP). (b) Flt1 reporter was validated by transducing human microvascular endothelial cells (HMECS). (c), Flt1 reporter containing rBMSCs were re-transduced with lentiviral vector expressing endothelial nitric oxide synthase (eNOS), eNOS + mutated caveolin- 1 (eNOS+CAV-1F92A), and eNOS+wildtype caveolin-1 (eNOS+CAV-1WT) following incubation in growth medium for up to 5 days, and GFP signal was detected by fluorescence microscopy. (d), RTqPCR analysis for FIt1 mRNA expression in transduced cells. $* p<0.05$ and $\# p<0.05$ vs. eNOS $+C A V-$ 1F92A (L-NAME), eNOS+CAV-1WT,CAV-LMT, CAV-1F92A, GFP and rBMSC. $(n=3)$

a

FIt1 activated GFP repoter

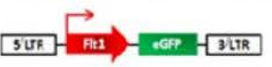

C
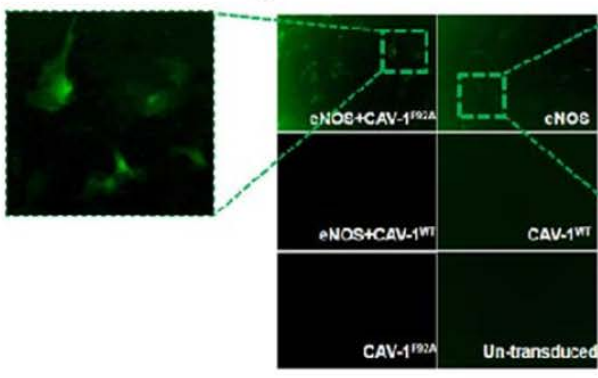

b

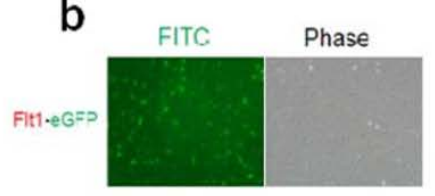

d

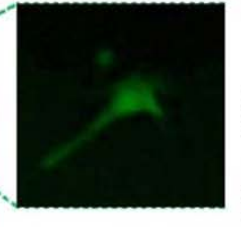

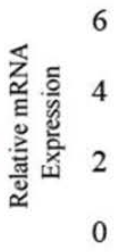

Figure 3

This article is protected by copyright. All rights reserved. 
Figure 4. Flow cytometry analysis of CD31 expression in reprogrammed cells. Flow cytometry analysis of cells transduced with LV- eNOS+CAV-1F92A and LV-eNOS showed $16.2 \%$ and $9.8 \%$ positivity for CD31 respectively. I nterestingly untransduced cells exposed to the NO donor NONOate $(10 \mu \mathrm{M})$ showed a similar level of CD31 expression $(9.1 \%)$ to the LV-eNOS cells. Treatment of LVeNOS +CAV-1F92A cells with the eNOS inhibitor, L-NAME abolished CD31 expression. Numbers embedded in each graph indicate the percentage of CD31+ cells. (SSC; side scatter). $\mathrm{N}=3$.
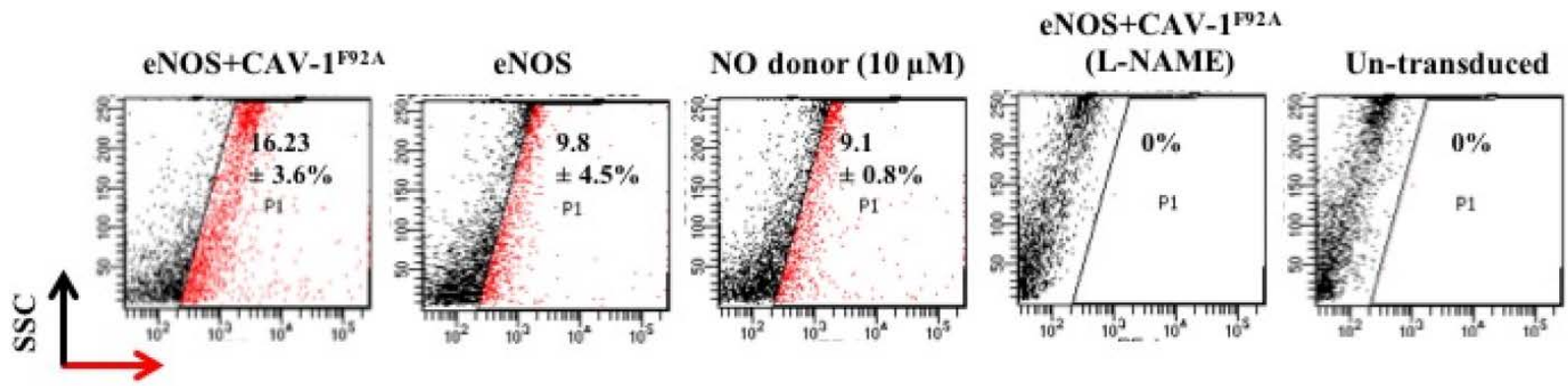

CD31

Figure 4

This article is protected by copyright. All rights reserved. 
Figure 5. Nitric oxide induces expression of arterial endothelial cell specific transcription factors. Relative mRNA expression of (a), arterial specific transcription factors DII4, Notch1, and Hey2 was up regulated in LV- eNOS+CAV-1F92A and LV-eNOS cells and expression was significantly reduced with L-NAME treatment. whilst (b), venous specific Coup-TFII and (c), lymphatic specific Prox 1 transcription factors were down regulated in eNOS-GFP and eNOS-GFP+CAV-1F92A transduced rBMSCs as assessed by quantitative real time PCR. $* p<0.05$ and $\# p<0.05$ vs. eNOS-GFP+CAV1F92A (L-NAME), eNOS-GFP+CAV-1WT, CAV-1WT, CAV-1F92A, GFP and rBMSC. $(n=3)$.
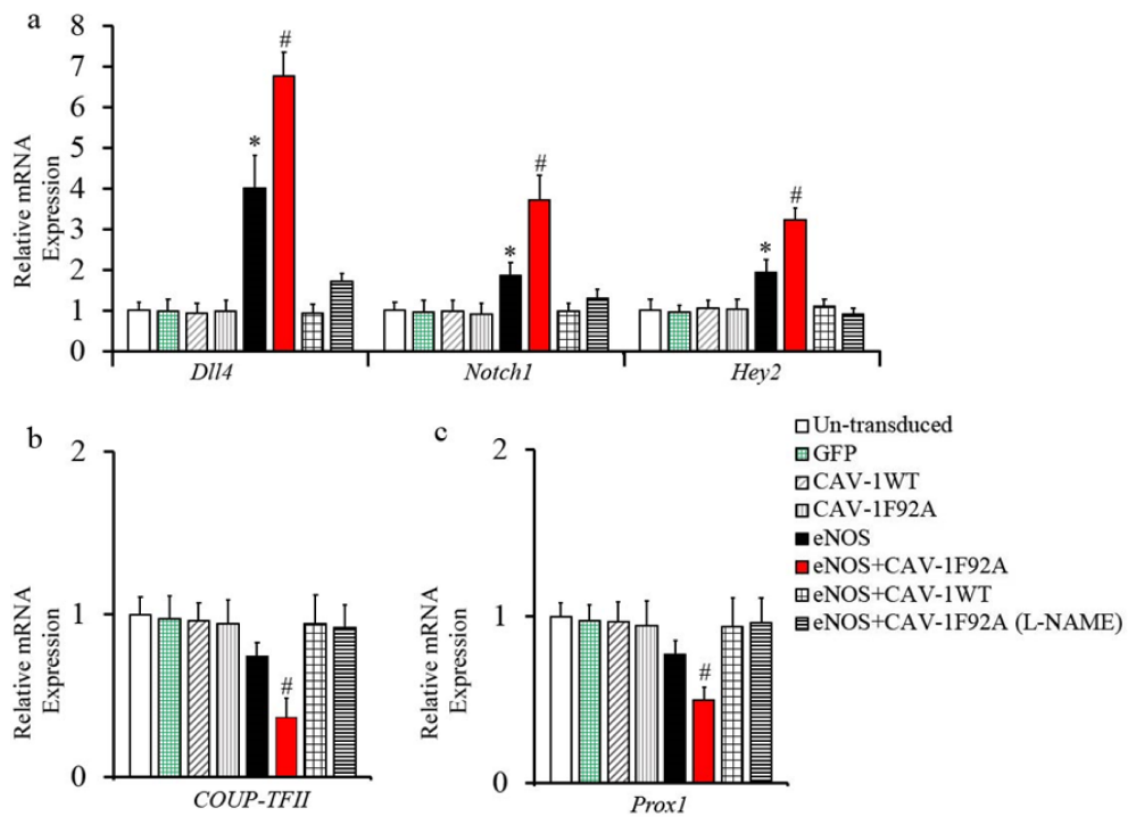

Figure 5

This article is protected by copyright. All rights reserved. 
Figure 6. Nitric oxide promotes endothelial reprogramming through canonical Wnt signalling. Relative mRNA expression of the (a), canonical Wnt3a and (b), endothelial Pecam-1 were upregulated in eNOS-GFP and eNOS-GFP+CAV-1F92A transduced rBMSCs as assessed by quantitative real time PCR. Treatment of eNOSGFP+ CAV-1F92A cells with L-NAME significantly reduced Wnt3a expression and treatment with the Wnt3a inhibitor, Dickkopf-related protein 1 (Dkk1) reduced expression of pecam-1. (c), Western blot analysis of $\beta$ - catenin expression in eNOSGFP+CAV-1F92A and LV-eNOS cells was also increased and L-NAME treatment of eNOS-GFP+CAV1F92A reduced expression. $* p<0.05$ and $\# p<0.05$ vs. eNOS-GFP+CAV-1F92A (L-NAME), eNOSGFP+CAV-1F92A (Dkk-1), eNOS-GFP+CAV-1WT, CAV-1WT, CAV-1F92A, GFP and rBMSC. $(n=3)$.

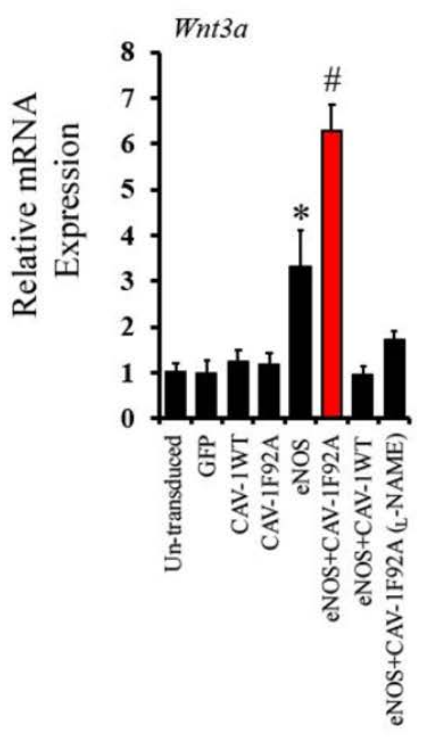

$\mathrm{b}$

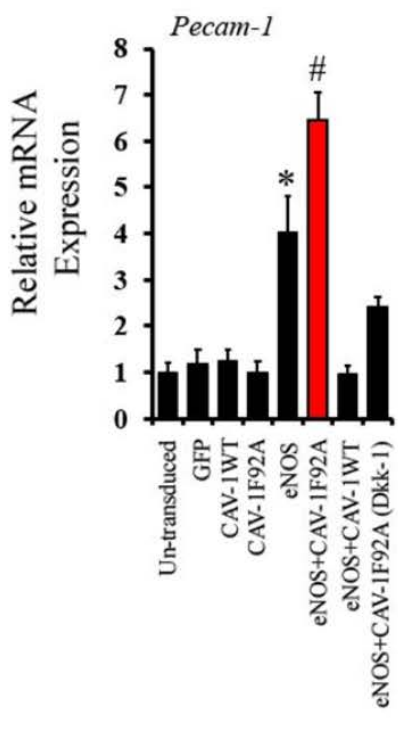

c

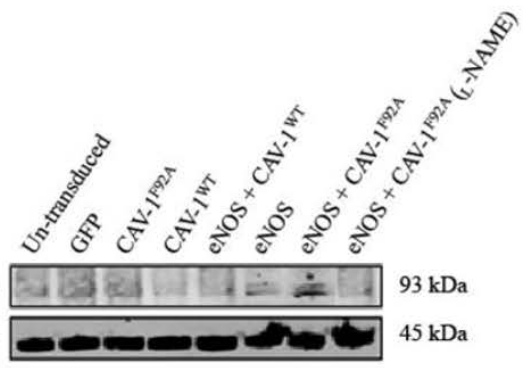

Figure 6

This article is protected by copyright. All rights reserved. 
Figure 7. Nitric oxide modulates DNA methyltransferase 1 expression and demethylates the Flt1 endothelial promoter. (a) DNA methyltransferase Dnmt1 mRNA expression was inhibited in LVeNOS-GFP+CAV-1F92A and LV-eNOS transduced cells and inhibition was reversed by L-NAME treatment. Expression of Dnmt3a and 3b was unaffected by nitric oxide (b), FIt1 promoter methylation analyses by bisulphite sequencing shows significant demethylation of CpG islands in eNOS-GFP+CAV-1F92A transduced cells compared to untransduced control cells. \#p<0.05 vs. eNOS-GFP, eNOS-GFP+CAV-1F92A (L-NAME), eNOS-GFP+CAV- 1WT, CAV-1WT, CAV-1F92A, GFP and rBMSC. $(n=3)$.

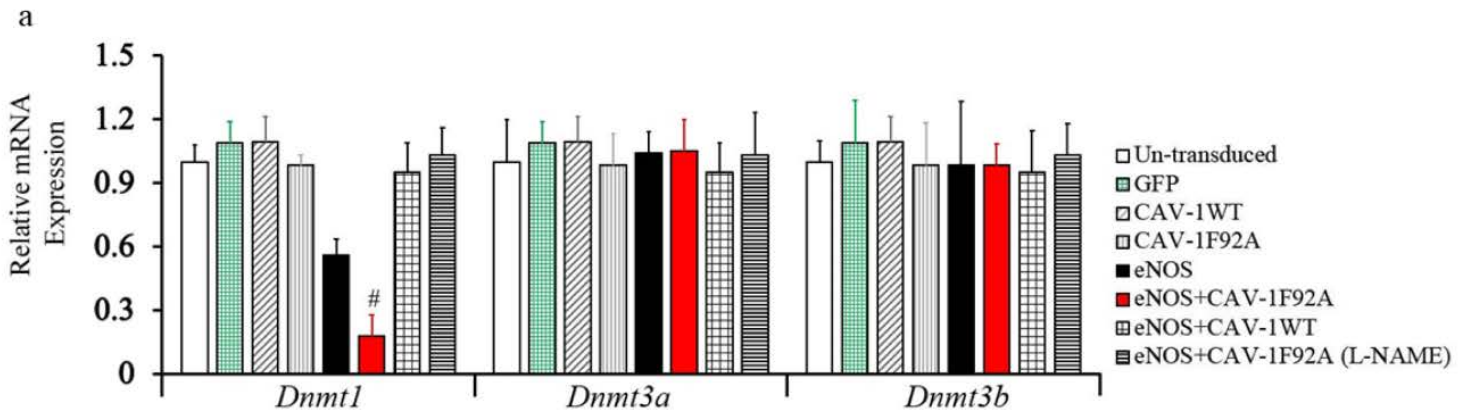

$\mathrm{b}$

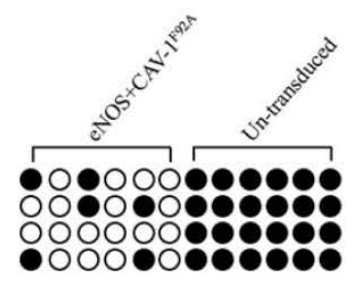

De-methylated

Methylated

Figure 7

This article is protected by copyright. All rights reserved. 
Figure 8. Subcutaneous transplantation of genetically modified rBMSCs in the SCID rat. (a), Genetically modified and un-modified rBMSCs were resuspended in fibrinogen and thrombin followed by seeding onto polyurethane scaffolds. After $1 \mathrm{~h}$ incubation at $37{ }^{\circ} \mathrm{C}$ in $5 \% \mathrm{CO} 2$, the scaffolds were transplanted under the skin of the dorsal side of nude rats and following 7 days post transplantation, the scaffolds were harvested and processed. for histological analysis by (b) hematoxylin and eosin, (c) lectin and (d) GFP immunostaining. Black arrows and red triangles indicate blood vessels and blue arrows and white triangle indicate scaffold material. $(n=3)$. The white arrow indicates the GFP positive cells and the yellow arrow indicates newly formed blood vessel associated with GFP positive cells. Scale bars $=0.05 \mathrm{~mm}$

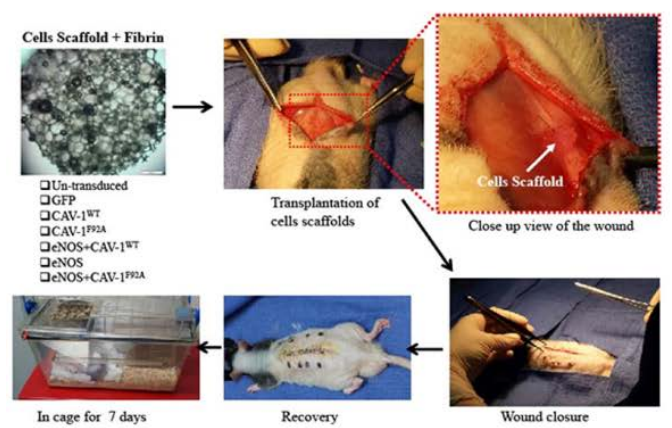

$\mathrm{b}$

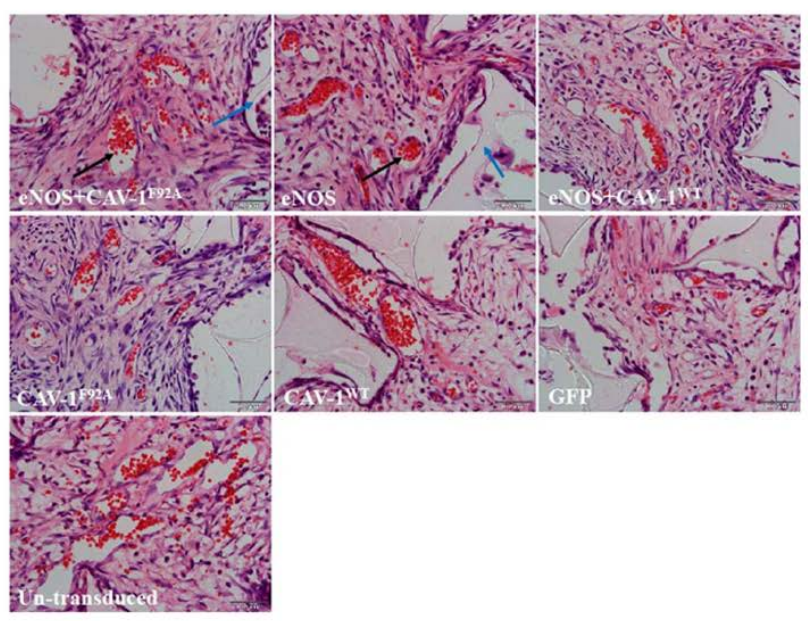

Figure $8(a, b)$

This article is protected by copyright. All rights reserved. 

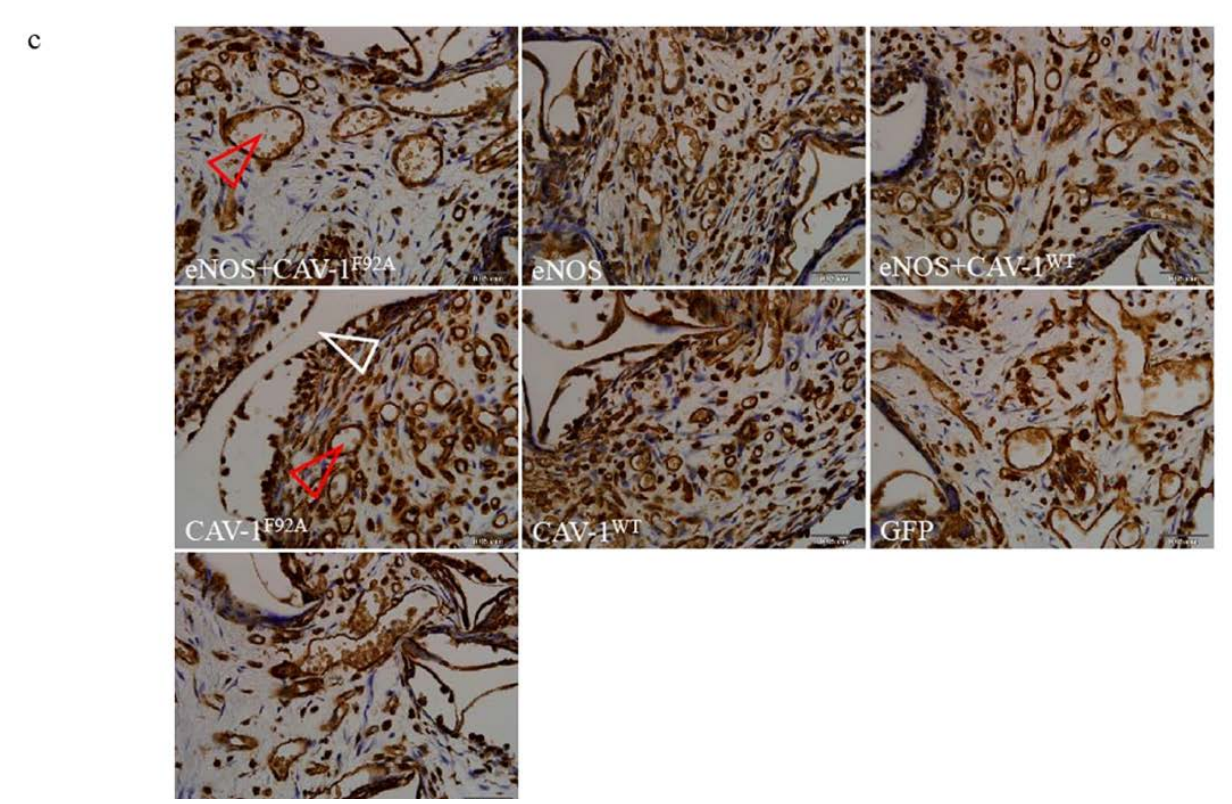

d
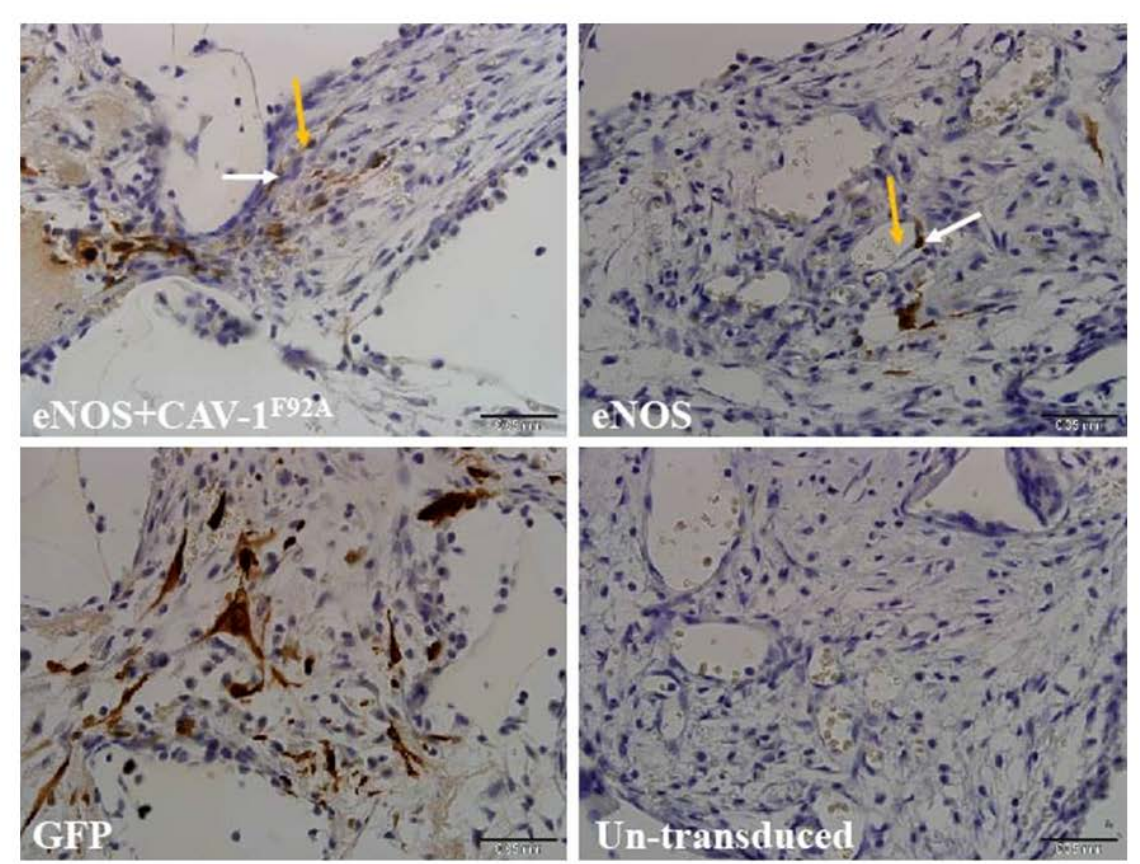

Figure 8(d)

This article is protected by copyright. All rights reserved. 
Figure 9. Proposed molecular mechanisms underlying nitric oxide mediated endothelial differentiation in rBMSCs. Molecular control of NO levels can promote endogenous Wnt/ छatenin signaling, addition, NO can inhibit DNA methyltrasferease Dnmt1 resulting demethylation of the endogenous Flt1 promoter region resulting in enhanced endothelial specific gene expression profiles and promotion of endothelial differentiation of bone marrow derived mesenchymal stem cells.

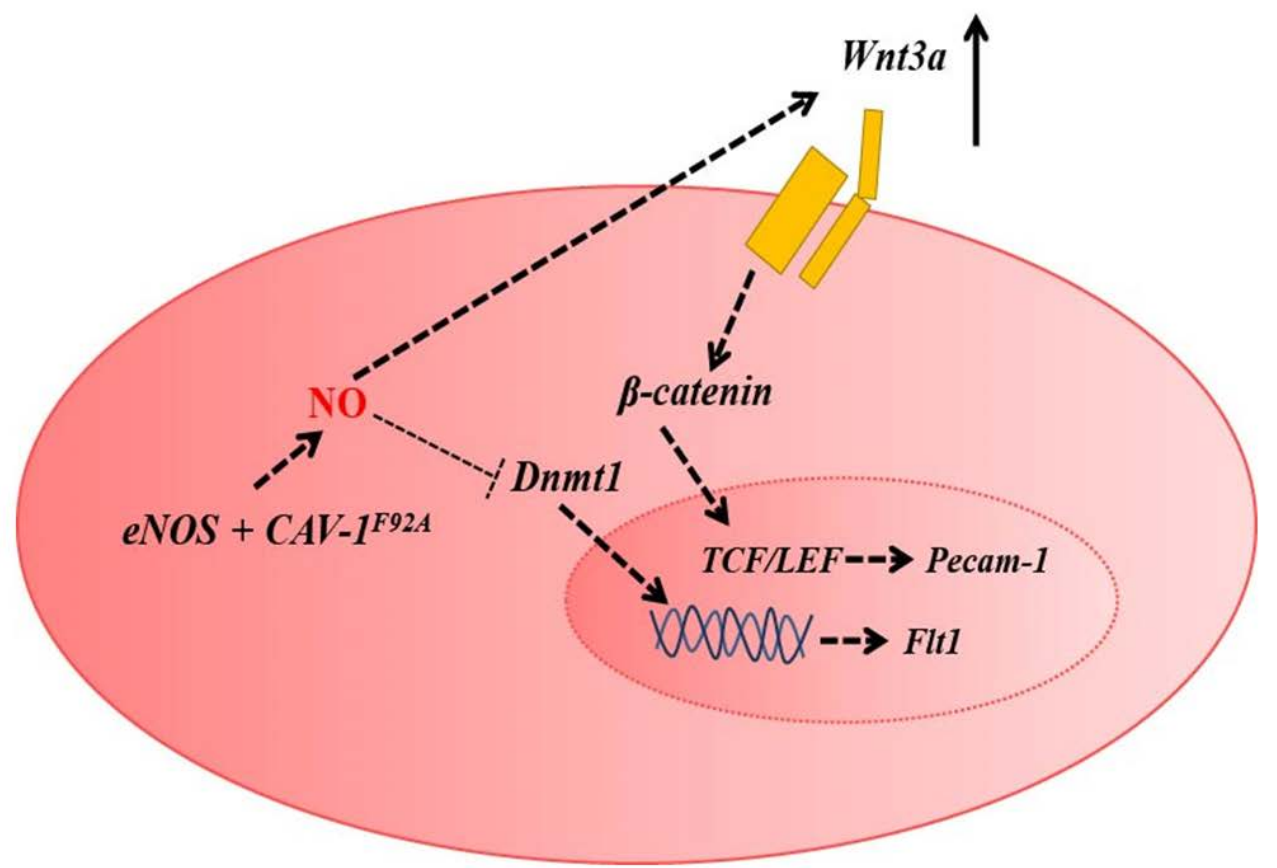

Figure 9

This article is protected by copyright. All rights reserved. 


\section{University Library}

\section{- M M I N E R VA \\ A gateway to Melbourne's research publications}

Minerva Access is the Institutional Repository of The University of Melbourne

Author/s:

Bandara, N;Gurusinghe, S;Kong, A;Mitchell, G;Wang, L-X;Lim, SY;Strappe, P

Title:

Generation of a nitric oxide signaling pathway in mesenchymal stem cells promotes endothelial lineage commitment

Date:

2019-11-01

Citation:

Bandara, N., Gurusinghe, S., Kong, A., Mitchell, G., Wang, L. -X., Lim, S. Y. \& Strappe, P. (2019). Generation of a nitric oxide signaling pathway in mesenchymal stem cells promotes endothelial lineage commitment. JOURNAL OF CELLULAR PHYSIOLOGY, 234 (11), pp.20392-20407. https://doi.org/10.1002/jcp.28640.

Persistent Link:

http://hdl.handle.net/11343/285758 